\title{
Millest kõnelevad ja millest vaikivad triibud Abhaasia lipul? Religioossest situatsioonist Abhaasias ${ }^{1}$
}

\author{
Aivar Jürgenson \\ Tallinna Ülikooli Humanitaarteaduste instituudi ajaloo, arheoloogia ja \\ kunstiajaloo keskuse vanemteadur \\ aivarj@tlu.ee
}

\begin{abstract}
Teesid: Abhaasias sajandeid kõrvuti eksisteerinud oma, nn abhaasi usk, kristlus ja islam on vorminud abhaaside maailmapilti, mis mõnede autorite hinnangul kannab tugevat sünkretistlikku varjundit. Uskude omavahelisi suhteid kirjeldatakse rahumeelsetena. Artiklis vaadeldakse Abhaasia usuelu ajaloolises perspektiivis ja püütakse leida seletusi tänasele religioossele situatsioonile. Samuti käsitletakse religioosset kuvandiloomet - abhaasi autorite pingutusi vabaneda grusiinide loodud abhaasi islamikuvandist kristliku kuvandi juurutamise abil. Ajaloolisi arenguid jälgides analüüsitakse artiklis mõistete sünkretism ja sekulaarsus kasutusvõimalusi abhaaside religioosse maailmapildi käsitlemisel.
\end{abstract}

Märksõnad: Abhaasia, islam, sekulaarsus, sünkretism, õigeusk

\section{Sissejuhatus}

Abhaasia riigilipu (kinnitatud Abhaasia Ülemnõukogu poolt 23. juulil 1992) graafika sarnaneb paljus USA, Libeeria, Malaisia või mõne muu riigi lipule: ristkülik vardapoolses ülemises nurgas, ülejäänud lipu pinda katavad kaht värvi triibud. Kui USA, Libeeria ja Malaisia lippudel vahelduvad punased triibud valgetega, siis Abhaasia lipul rohelised valgetega - rohelised tähistavad islamit, valged kristlust. Triipude vaheldumine sümboliseerib kahe religiooni sajanditepikkust rahumeelset kooseksisteerimist. Rahu sümboliseerib ka avatud peopesa punasel ristkülikul. Tegelikult on sajandite jooksul Abhaasias religiooni pinnal ja religioossetel ajenditel toimunud nii mõndagi, kuid tänapäeval eksisteerivad kaks religiooni rahumeelselt teineteise kõrval. Kuna religioonide sõbralik kooseksisteerimine on suuresti tänase globaalse maailma väljakutse, on Abhaasiat esitatud hea orientiiri ja eeskujuna muule maailmale - ka nii on võimalik elada. Abhaasia kui unikaalne näide islami ja kristluse rahumeelsest üksteise kõrval eksisteerimisest esineb mitmete teemat käsitlenud abhaasi 
autorite (Ešba 2012: 8; Gumba 2011: 325; Atšugba 2011b: 220) tekstides. Kohati on teesi kasutanud ka vene autorid (Šamba \& Neprošin 2004: 16).

Lisaks kahele maailmareligioonile on tänaseni Abhaasias suhteliselt elujõuline ka kohalik loodususk, omakeelse nimetusega апсуа нивахацара ehk abhaasi usk, ${ }^{2}$ milles esinevad nii jumalate hierarhia, arvukad haldjad kui ka animatistlikud väekujutelmad. Abhaasi usk on üle elanud kristluse varasema ja islami hilisema tulemise. Kolme religiooni üksteise kõrval eksisteerimine on ajendanud mõningaid abhaasi autoreid rääkima abhaaside sünkretistlikust maailmapildist (nt Kvitsinija 2012: 185-187; Broido 2010: 64; Basarija 2003: 62).

Käesolevat artiklit ajendas kirjutama ühelt poolt huvi Abhaasia religioosse situatsiooni vastu, teisalt intriigina ka üldisem küsimus sünkretismi olemusest ja mõiste kasutusvõimalustest. Kas ja millisel määral peegeldab sünkretism mõistena adekvaatselt Abhaasia religioosset olukorda? Küsimusele vastamiseks on põhjust süüvida Abhaasia religioonilukku selle ajaloolises arengus ja sotsiaalpoliitilises kontekstis, vaadelda võimalikke sünkretismi, aga ka sekulaarsuse ilminguid, nende omavahelist vahekorda ja funktsionaalseid seoseid.

\section{Sünkretism}

Religioosne sünkretism on kultuuriprotsess, mida võib mõista osana laiemast kultuuridifusiooni protsessist. Kuigi sünkretism võib tähendada kultuurijoonte kooseksisteerimist avaramas tähenduses, kasutatakse mõistet enamasti siiski seoses religiooniga (Braukämper 1992: 194).

Nähtust on käsitlenud nii religiooniloolased kui kultuuriantropoloogid. On näidatud, et sünkretism ilmneb kultuuri või tema elementide kandumisel ühelt etniliselt grupilt või kultuuriväljalt teisele etnilisele grupile või kultuuriväljale. Mõiste tuleneb kreeka verbist "synkerannumi" (kokku segama) ning ajalooliselt on sellega tähistatud religioosset korratust, piibli teoloogid on sellega iseloomustanud kreeka-rooma paganlust vastukaaluks kristluse normatiivsusele, protestandi teoloogid on sellega tähistanud roomakatoliikluse eemaldumist oma ajaloolistest lätetest. Seega religioosne segadus "isade usu" vastu (Martin 2014: 287). Kokkuleplust ja sünkretistlikke võõrmõjusid on kiriku ajaloos nähtud pigem hereesiana, mis puhast usku rikub ja usklikke eksitab. Reformatsiooni ajal vaieldi, kui kaugele võib minna usuliste eriarvamuste aktsepteerimisel. Kui luteri teoloog Georg Calixtus (1586-1656) toetas eri protestantlike suundade ühinemist ja lõpuks taasühinemist katoliku kirikuga, siis tõrjusid tema visiooni oikumeenilisest kristlusest nii ortodokssed luterlased kui ka katoliku kiriku ladvik. Oponentide meelest ohustas Calixtuse propageeritud taasühinemine kirikut eri õpetuste hereetilise segadikuga. 17. sajandi jooksul peetud 
sellesisulised debatid said tuntuks kui "sünkretistlikud vaidlused". Negatiivne tähendusvarjund religioossele segule oli ootuspärane, eriti katoliku kiriku poolt, kes pidas end oma dogmade ja õpetuse usulise puhtuse järelvaatajaks terves maailmas. Kui eurooplaste ülemerekolooniates tegutsenud kiriku ametikandjad hakkasid misjoni kontrolli alt väljuma ja teatud aspekte põliselanike religioonidest aktsepteerima, selle asemel et vahendada kristluse euroopalikku vormi, sai "sünkretismist" märksõna selliste kuritarvituste tähistamiseks (Stewart 1999: 46).

Mõistetena saab seega rääkida sünkretismist kui võooraste religioossete elementide omaksvõtust ja antisünkretismist kui kiriku püüdest sünkretismi vältida ja kaitsta puhta religiooni piire - kuigi iroonilisel kombel on just kristlik misjon kaasa aidanud sünkretistlike nähtuste esiletõusule. Mitmed autorid on õigusega rõhutanud, et sünkretismi tuleb käsitleda tema spetsiifilises ajaloolises, kultuurilises ja poliitilises kontekstis. John A. North (1984: 317) kirjutab, et religioosne sünkretism on erinevate traditsioonide elementide ilmnemine poliitilise või kultuurilise domineerimise või allumise tingimustes. Nii et religioosse segunemiseni viivad mitte üksnes kultuuridevahelised kontaktid, vaid ka ebavõrdsed poliitilised või kultuurilised suhted. Michael Pye möönab, et elemendid, mis on kaasatud sünkretistlikku religioossesse situatsiooni, ei pea olema kõik tingimata religioosset päritolu, vaid võivad hõlmata poliitilisi, filosoofilisi jm sekulaarseid elemente (Pye 2014: 57).

Poliitilise võimu mõjust sünkretismi kujunemisel võib tuua läbi ajaloo hulgaliselt näiteid - sellest, kuidas impeeriumide territooriumidel elavad rahvad annavad oma kohalikele vaimolenditele impeeriumi jumaluste nimesid jne. James Huntley Graysoni meelest on sünkretismil vähemalt kaks vormi, mis võivad ilmneda mõne maailmausundi ja kohaliku usundi kokkupuutel. Esimese variandi, nn madala sünkretismi määra puhul lisab misjonireligioon kohalikku religiooni väliseid vorme ja pinnapealseid jooni, kohaliku religiooni tuumväärtused jäävad aga uues religiooni vormis püsima. Teise variandi, nn kõrge sünkretismi määra korral, saavad misjonireligiooni tuumväärtused uues religioonis keskseks, samas kui kohalik usund pakub teatavaid teisejärgulisi detaile. James Huntley Grayson leiab, et sünkretistlik pööre on toimunud siis, kui "vanasse" religiooni võetakse üle "uue" religiooni tuumväärtused. Kui aga vahetuvad vaid religiooni välised jooned, kuid väärtused jäävad samaks, võib öelda, et sünkretismi protsess on pinnapealne. Tavaliselt mõistetakse religioosse sünkretismi all just väliste joonte muutumist mõne misjonireligiooni mõjul. Ise toob James Huntley Grayson taolisi näiteid korea põlisusundi kohanemisprotsessist budismiga (Grayson 1992: 202-205).

Siinkirjutaja meelest varieerub religioonide "valmisolek" uuendusteks sõltuvalt religiooni vormist. Nn raamatureligioonide nagu kristluse või islami 
peavooludes on nende väärtused fikseeritud pühakirjas - just pühakirja sakraalne fikseeritus annab pühakirjale toetuvatele usudogmadele autoriteedi. Kui kohati on väidetud, et sünkretism on omane mitte-kristlikele religioonidele (vt Leopold \& Jensen 2014a: 379), siis üheks põhjuseks on nende religioonide kirjaliku fikseerituse puudumine. Kristluse agenda on olnud läbi ajaloo valdavalt puristlik ja antisünkretistlik, mis raamatureligiooni seisukohalt on ka mõistetav: kõrvalekaldeid piibli õpetusest tõlgendatakse hereesiana, sest just piibel sõnastab kristluse tuumväärtused. Kui õpetust toetab poliitiline võim, võib olla tulemuseks teiseusuliste tagakiusamine, mille kohta pakub Euroopa ajalugu hulgaliselt näiteid nii kontinendi-siseselt kui ka seoses koloniaalvallutustega, mille maiseid ambitsioone õigustati suuresti just kristianiseerimise vajadusega. Abhaasias, nagu järgnevalt näeme, on religioosse purismi agendaga põhjendatud maa põliselanike pagendamist (kuigi tegelikud eesmärgid olid mittereligioossed). Samas võivad poliitilised agendad õhutada purismi asemel hoopis sünkretismi - Abhaasiast leiab ka selle kohta näiteid. Samas leian, et religioonide pikaajalisest kõrvuti eksisteerimisest ei tarvitse tingimata tuleneda sünkretistlikke tendentse, post-kristlikke või post-islamlikke arenguid. Religioonil on tugev identifitseeriv funktsioon, ta loob kuuluvust ka juhul, kui religiooni kandjad teadvustavad peamiselt vaid religiooni tuumväärtusi. End mõne religiooni kaudu identifitseerivad inimesed ei pea olema tingimata peensusteni kursis religiooni dogmaatiliste nüanssidega. Kaukaasia pakub selle kinnituseks näiteid mitmelt poolt, sh Abhaasiast.

Religioosne pluralism võib sõltuvalt poliitilisest agendast asenduda purismiga, sünkretism antisünkretismiga. Juba aset leidnud sünteesiprotsessid võivad võtta vastupidise suuna. Bosnias olid moslemid millalgi õigeusklike head naabrid ja kaas-jugoslaavlased, siis aga said vaenlasteks. Mõne vaate kohaselt olid Bosnia moslemid "tegelikult" serblased või horvaadid, keda sunniviisiliselt islamiseeriti Ottomanide võimu ajal ja keda oli nüüd vaja dehübridiseerida ning pöörata tagasi varasemasse etnilisse sängi (Stewart 1999: 54). Abhaasia ajaloos on poliitilised agendad pööranud religioone kord üksteise vastu, kord õhutanud sümbioosi, kord toonud esile ühe või teise religiooni identifitseeriva rolli. Esimese näitena esitan sündmuse lähiajaloost, mis toob esile Abhaasia esitamise islamimaana grusiinide poolt ja selle kuvandi kummutamiskatsed abhaaside poolt. Selleks on Gruusia-Abhaasia sõda. 


\section{Kas Gruusia-Abhaasia sõda oli ususõda?}

Kui aastatel 1992-1993 toimus Gruusia-Abhaasia sõda, kus Gruusia tungis Abhaasiasse sealseid separatistlikke meeleolusid maha suruma, siis esitas Gruusia propagandamasin seda kohati ususõjana: grusiinid-kristlased seisid sõjas vastamisi abhaaside-moslemitega või koguni islamifundamentalismiga (Broido 2010: 66; Avidzba 2008: 148). Tegelikult peab suurem osa abhaase tänapäeval end kristlasteks (60\% rahvastikust).

Äraspidistest ettekujutustest Abhaasia religioosse situatsiooni kohta annab tunnistust näiteks see, kuidas juba enne sõda suvel 1992 saabus Gruusiasse ja ka Abhaasiasse CSCE (hilisem OSCE) diplomaatiline missioon. Diplomaadid kohtusid Abhaasia Ülemnõukogu liikmete, poliitiliste organisatsioonide ja rahvusgruppide esindajatega. Pärast paaritunnist viibimist Abhaasias pöörduti tagasi Tbilisisse. Kui ilmus nende ametlik raport, olid abhaasid šokeeritud. Euroopa diplomaadid väitsid nimelt, et suurem osa abhaasidest järgib islamit. See müüt rändas veel kaua ühest ettekandest teise ja muidugi ka ajakirjandusse. Sügisel 1992, kui sõda oli juba alanud, esines Gruusia president Eduard Ševardnadze ÜRO peaassambleel kõnega, rääkides fundamentalismi ohust, mis ähvardab maid Tadžikastinist idas kuni Bosniani läänes, viidates ka sellele, et sõja Abhaasias kutsusid esile just need jõud (Akaba 2000: 18).

Selline grusiinidepoolne kuvandiloome sai toitu asjaolust, et sõjas osales abhaaside poolel tõesti mitu tuhat vabatahtlikku võitlejat Põhja-Kaukaasiast tšetšeenid, inguššid, kabardiinid, tšerkessid jt. Kuid abhaaside poolel võitles ka õigeusklikke ja katoliiklasi, samuti luterlasi, sh kohalikke eestlasi. Nii ei ole mingit põhjust pidada seda sõda ususõjaks.

Sellise vastanduse juured on tegelikult kaugemal minevikus. Kogu viimase aastatuhande on Kaukaasia kristlased pidanud seisma vastu islamimaade Türgi ja Iraani hegemooniataotlustele ja pikemat või lühemat aega taluma nende valitsemist koos kõige selle juurde kuuluvaga. Seetõttu on grusiinid tajunud end selles piirkonnas kristluse eelpostina moslemite vastu (Akaba 2000: 17). 1990. aastate alguses juurutati Gruusias nn "gruusia militaarse kristluse" ideed, mida eelkõige seostatakse tollase esoteerikust ja antroposoofist presidendi Zviad Gamsahurdiaga. Tema oli ka see, kes rakendas Gruusia kaitsepühaku, lohega võitleva Püha Jüri oma ilmselgelt šovinistlike võimuambitsioonide teenistusse (Manutscharjan 2009: 72).

Gruusia-Abhaasia sõda lõppes, abhaasid vabanesid grusiinide ülemvõimu alt, kuid nimetatud käibearvamus ei kadunud. 1990. aastatel juhtus ikka ja jälle, et kui Lääne diplomaadid sõitsid Abhaasiasse läbi Gruusia, oli neid juba informeeritud Abhaasiast kui moslemimaast. Abhaasias pidid diplomaadid imestusega nentima, et seal peetakse jõule ja ülestõusmispühi. Kedagi USA 
diplomaati oli Gruusias hoiatatud, et tal tuleb hakata uut aastat vastu võtma moslemite keskel (Akaba 2000: 17).

Veel üks põhjus, miks Gruusia propaganda üritab abhaase seostada moslemitega, võib olla selles, et viimasel veerandsajandil ja eriti viimasel tosinal aastal Läänele lähenedes on Gruusia sageli väljendanud rahutust islami fundamentalismi pärast Kaukaasias. Ühise vastase otsimine seega, mis seletub Gruusia NATO-sse pürgimisega. Peab arvestama ka sellega, et Gruusias on mitmeid suuri moslemikogukondi (kistid ehk kistiinid, aserid, adžaarid, avaarid) (Lakoba 2001: 107). Sellel taustal, aga ka maailmas üha süveneva islamihirmu foonil võib Abhaasia-Gruusia sõjale tagasi vaadates selle nn moslemi faktor hakata paistma tegelikkusest suurem.

Abhaasia kui islamimaa kuvand on visa kaduma. Ikka ilmub teoseid, milles Abhaasiat nimetatakse moslemimaaks või "peamiselt moslemimaaks" (nt Smele 2015: 145). Seetõttu pole kadunud ka ettekujutus Gruusia-Abhaasia sõjast kui ususõjast. Õnneks on ka tähelepanelikumaid autoreid, kes selle eksiarvamuse eest hoiatavad. Meil on näiteks Mart Helme kriitiliselt suhtunud seisukohta, mis püüab abhaaside ja grusiinide vahelised vastuolud viia religioossele pinnale (Helme 2008: 24).

Abhaasi autor Natella Akaba leiab, et stereotüüp abhaasidest kui moslemitest taandub tegelikult kujutlusele abhaasidest kui mitte-grusiinidest (Akaba 2000: 17). Selle viimasega, abhaaside ja grusiinide etniliste piiride rõhutamisega, abhaasi autorid muidugi nõustuvad ja rõhutavad nende kahe rahva erijooni oma teostes innukalt. Abhaaside etnogeneesi teema on tugevalt esil ka näiteks Abhaasias kasutatavates kooliõpikutes, mis ühelt poolt rõhutavad abhaaside põlisust oma kodumaal ning teiseks abhaaside ja grusiinide etnogeneetilist erinevust (nt Bgažba \& Lakoba 2016).

Kui gruusia autorid üritavad toonase sõja puhul rõhutada usufaktorit ja toovad selles seoses esile abhaaside ja põhjakaukaaslaste religioosseid seoseid, siis abhaasi autorite käsitluses ei taheta Põhja-Kaukaasia mägirahvaste abis näha mitte usulise, vaid eelkõige keelelis-kultuurilise ühtsuse ja sellest tuleneva solidaarsuse väljendust. Abhaasi humanitaarteadlased peavad keelt peamiseks etniliseks markeriks, millega argumenteeritakse abhaaside ja grusiinide erinevust. Samal ajal, selgitusega, et keel on iga rahva vaimse elu alus, põhjendatakse sidet Põhja-Kaukaasia sugulasrahvastega (Šamba \& Neprošin 2004: 9). Abhaasia-Gruusia sõda näidatakse isamaasõjana, kus hõimurahvaste abiga vabastati kodumaa agressorist. 


\section{Kristluse ajaloost Abhaasias}

Kuivõrd tees Gruusia-Abhaasia sõjast kui ususõjast on antisünkretistlik, selgelt on esil eraldusjoon kristluse ja islami vahel, on ka selle teesi vastased olnud sunnitud kasutama sama malli: Abhaasiat näidatakse "põlise" kristliku maana, kus islam on hiline ja võrdlemisi pealiskaudne uustulnuk. Kui Gruusia on end esitlenud kristluse eelpostina Kaukaasias ja vastandanud usu alusel teiste seas ka abhaasidele, panevad abhaasi autorid oma töödes suurt rõhku Abhaasia kristliku tausta väljatoomisele. Rõhutatakse maa pikaajalisi kristlikke traditsioone ja kristluse jõudmist tänapäeva Abhaasia alale juba 1. sajandi keskpaiku pKr - maaletoojaks on legendide kohaselt Jeesuse jünger Siimon Kananaios (Mt 10: 4) isiklikult. Näidatakse, kuidas 3. sajandil sai Pitiuntist (tänapäeva Pitsunda) Rooma impeeriumi kristlaste väljasaatmise koht, seda, kuidas 3.-4. sajandil kujunes Pitiuntis üks vanemaid Kaukaasia kristlikke kogukondi. ${ }^{3}$ Rõhutatakse, et 325. aastal võttis Pitiunti piiskop osa kirikuloos kuulsast Nikaia kirikukogust, seda, et 6.-7. sajandil sai kristlus peaaegu kogu Abhaasia territooriumil ametlikuks usuks (Lakoba 2004: 9; Broido 2010: 63; Atšugba 2011a: 16-19).

See oli aga aeg, mil Abhaasia kuulus Bütsantsi mõjusfääri. Nagu tavaks, ehitati kristlikud pühamud senistesse loodususu pühapaikadesse. Näiteks rajas Bütsantsi keiser Justinianus 6. sajandil ühte abasgide ${ }^{4}$ pühapaika Jumalaemale pühendatud kiriku. Tänapäeval üks tuntumaid, Ilori kirik rajati samuti endisele pühapaigale. Arvatakse, et Iloris asus abhaaside hõimujumala Elõr-Nõha pühapaik. Elõr-Nõha auks on seal ohverdusi läbi viidud ka hiljem. Väidetakse, et jutlusi neofüütidele peeti 6. sajandil ka abhaasi keeles (Tsakvetadze 2009: 66). Nimetatud Justinianus laskis Abhaasiast tuua lapsi Konstantinopolisse neile rajatud kooli haridust omandama. Ilmselt oli tegemist vaimuliku õppeasutusega, et valmistada Abhaasiale ette vaimulikke ja Bütsantsi poliitika elluviijaid (Kaslandzija 2012: 74).

8. sajandi lõpul tekkis mitme kohaliku vürstiriigi ühendamisel Abhaasia kuningriik, mille esimene valitseja Leon II kuulutas end 787. aastal Bütsantsist sõltumatuks. On vaieldud, kas Abhaasia õigeusukirik iseseisvus kohe pärast seda või jätkas veel mõned aastakümned Konstantinoopoli patriarhaadi alluvuses. Tuuakse esile 9. sajandi algusest pärit allikas Notitiae episcopatuum, mis nimetab Abasgi autokefaalse kiriku juhina Sebastopoli (Suhhumi tollane nimetus) peapiiskoppi. Teemat käsitlenud autorid peavad oluliseks rõhutada, et allikatest järeldub Abhaasia katoolikose (kirikupea) sõltumatus Mtsheta katoolikosest ehk tänapäeva mõistes Gruusia õigeusukiriku peast. Rõhutatakse, et pigem oli esimene teisest tollal olulisem (Kaslandzija 2012: 75, 85). 
Kahtlemata tuleb selliste rõhuasetuste korral meeles pidada Abhaasia ja Gruusia kirikute tänast konfliktset vahekorda, millest tuleb juttu allpool.

Vähe sellest, et Abhaasiat esitatakse Abhaasia ajalookirjutuses põlise kristliku maana, rõhutatakse ka asjaolu, et tänu oma poliitilisele ja geograafilisele asendile mängis Abhaasia olulist rolli Põhja-Kaukaasia rahvaste ristiusustamisel. Näiteks pööratud alaanid ${ }^{5}$ kristlusse abhaasi vürstide initsiatiivil. Samas võtmes rõhutatakse Nestori kroonikale tuginedes, et Kiievi Sofia kiriku ehitamisel osalesid ka abhaasid (Basarija 2003: 14). Selliseid fakte toovad abhaasi ajaloolased välja kindlasti osalt ka vastusena gruusia autorite väidetele, mille kohaselt olid kristluse levitajateks piirkonnas grusiinid ja et abhaasidel polnud sellega midagi pistmist (nt Totadze 1994: 23).

Kui 13. sajandi lõpust kuni 15. sajandini leidis Abhaasia rannikule aset Genua kolonisatsioon ja rannikule asutati genualaste kaubandusfaktooriaid, tegutsesid abhaaside seas ka katoliku misjonärid. Suhhumis (Sebastopolis või ka San Sebastianis) asus katoliku surnuaed. Katoliku misjonil suuremaid tulemusi siiski ei olnud, mida põhjendatakse sellega, et õigeusk oli selleks ajaks juba tugevasti juurdunud (Tsakvetadze 2009: 166). Oma osa oli kindlasti ka genualaste kolonisatsiooni lühiaegsusel ja tõigal, et suurem osa maast kuulus endiselt Bütsantsile.

Igatahes rõhutavad teemat käsitlenud Abhaasia autorid õigeusu põlisust Abhaasias ja sõltumatust Gruusia õigeusukirikust. Oluline on see grusiinide väidete taustal, mis ühelt poolt seovad Abhaasia õigeusukirikut Gruusia omaga, teiselt poolt aga on esitanud abhaase islami rahvana.

\section{Islami ajaloost Abhaasias}

Abhaasidest kui moslemitest saab kindlasti rääkida seoses varase abhaasi diasporaaga. Keskaegses Lähis-Idas moodustasid orisõduritest mehitatud kaliifi kaardiväe, keda tuntakse mamelukkide nime all, peamiselt Kaukaasiast ostetud noormehed. 1250. aastal haarasid nad võimu Süürias ja Egiptuses, kus valitsesid aastani 1517. Nende sultanid olid kas tšerkessi või abhaasi päritolu, ja muidugi olid nad võtnud vastu ka islami (Kaslandzija 2012: 85). Ka pärast mameluki dünastiate hääbumist jäid kaukaaslased Lähis-Idas mängima olulist rolli. Peeter Esimese võitluskaaslane Dmitri Kantemir kirjutas, et Egiptuses hinnatakse väejuhtidena kõige rohkem tšerkesse ja abhaase (Bartsõts 2012: 94). 1757. aastal sai Egiptuses šeik al balad'iks, st tähtsaimaks võimukandjaks, mees nimega Ali-bei, kes oli sündinud 1728. aastal Abhaasias õigeusu vaimuliku peres. Noorukieas olid orjakaupmehed ta röövinud ja müünud Egiptusse. Seal sai ta hea hariduse ja võttis vastu islami. Samas on märgitud, et kui ta juba 
võimul oli, mängisid tema kaaskonnas olulist rolli kristlastest nõunikud, eriti veneetslane Carlo Rosetti ja terve rida Süüria kristlasi. Levisid kuuldused, et Ali-bei Ukrainast pärit abikaasa, kuigi islamisse pöördunud, jäi salaja edasi kristlaseks (Kadõrbajev 2014: 48).

Abhaasia enda islamiseerimine ei alanud aga enne 15. sajandit. Kui 1453. aastal vallutasid türklased Konstantinoopoli, olid sellega Bütsantsi impeeriumi päevad loetud. Selle valdused läksid üle türklastele, nii ka Abhaasia. Ühes poliitilise võimu vahetumisega algas 15 . sajandil ka islami järkjärguline sissetung. Kuigi moslemi valitsejatel ei olnud tavaks kristlust keelustada, tehti islamisse astujaile mitmesuguseid soodustusi ja see avaldas pikapeale oma mõju. Islamit levitasid Abhaasias peamiselt Põhja-Kaukaasia moslemid, kuid see ei tõrjunud kunagi kristlust ja kohalikku abhaasi usku lõpuni välja. Tugevamini kinnitas islam kanda mägiasulates. Sinna ehitati palvetamiseks väikesed puust mošeed, oma isiklikud mošeed olid ka osadel feodaalidel (Tsakvetadze 2009: 87-88).

Abhaasia islamiseerimise puhul 15.-16. sajandil rõhutavad abhaasi autorid, et uus usk puudutas esialgu peamiselt abhaasi ülikkonda ja oli kantud poliitilistest kaalutlustest. Toonitatakse, et islam ei surunud päriselt välja kristlikke ja animistlikke arusaamu ega kombeid, mis kokkuvõttes andis aluse ainulaadsele sünkretistlikule maailmapildile (Broido 2010: 64; Basarija 2003: 62).

Osalt on see kooskõlas usulise situatsiooniga teiste (Põhja-)Kaukaasia väikerahvaste juures tol perioodil toimunuga. Ameerika ajaloolane Charles King kirjutab, et usuline kuuluvus on olnud Põhja-Kaukaasias võrdlemisi formaalne: nii islami kui ka kristluse järgijad on tarvitanud alkoholi, nad olid religioossetest võimudest kaugel ja sünkretistlikud (King 2012: 73). Ottomanide ja pärslaste misjon küll toimus, kuid tooni andsid pigem islami pealiinist kõrvalekalduvad sufi vennaskonnad. Islam oli detsentraliseeritud ja erines oluliselt mošeede ja mulladega linlikust islamist. See lõi eelduse põlisusundiliste rituaalide ja põhimõtete säilimisele. Rahvas oli valdavalt kirjaoskamatu ja nagu on kirjutatud, praktiseerisid Põhja-Kaukaasia mägilased eklektilist segu kristlikest, moslemi, juudi ja paganlikest rituaalidest. Erandi moodustas vaid Dagestan, kus alates 17. sajandist oli araabiakeelse islami kirjanduse traditsioon (Jersild 2000: 519-520, 522).

Eelnevalt tutvustatud James Huntley Graysoni sünkretismi tüpoloogias esindab Põhja-Kaukaasia ja sellega kultuuriliselt sarnase Abhaasia tollane religioosne situatsioon selle esimest varianti, madala sünkretismi määra, mille puhul võtab kohalik religioon misjonireligioonilt üle väliseid vorme ja pinnapealseid jooni, kohaliku religiooni tuumväärtused jäävad aga uues religioonivormis püsima. Põlisusundilises keskkonnas kujunenud kohalikud tavaõiguslikud eetikanormid on lisaks abhaasidele püsinud ka tšetšeenidel, inguššidel, kabardidel ja teistel sealsetel rahvastel läbi sajandite. 


\section{Venelaste tulek ja uus kristianiseerimine}

18. sajandi lõpul laiendas Venemaa tunduvalt oma piire lõuna poole. 1783. aastal vallutati Türgi sõltuvuses olnud Krimmi khaaniriik. Tungiti ka Põhja-Kaukaasiasse, mis samuti kuulus Türgi mõjualasse. Imperialistlikku ekspansiooni õigustati muuseas ka religioossete argumentidega. Nii näiteks ohustasid venelaste arvates Põhja-Kaukaasia väikerahvaid Ottomani ja pärsia misjon, mis ähvardas neid ära lõigata Bütsantsi ja kristlikust minevikust (Jersild 2000: 519). Venemaa, mis pidas end Bütsantsi järglaseks (nn Kolmas Rooma), õigustas sissetungi vajadusega päästa selles regioonis kristlus. Peab tähelepanu juhtima ka sellele, et Kaukaasia puhul ei saa usulise kuuluvuse põhjal teha järeldusi tollaste poliitiliste eelistuste kohta. Moslemid ei olnud alati venelaste vastu ja kristlased poolt. Kaukaasias oli moslemeid, kes liideti suhteliselt kerge vaevaga (põhjapoolsete tasandike kabardid, edelaosa moslemitest karjakasvatajad), ja kristlasi, kes panid südilt vastu (mõned Abhaasia vürstisuguvõsad, Lääne-Gruusia imereedid). Charles King teeb sellega seoses üldistuse, et Kaukaasias pole olnud ühtset islamit ega ühtset islamivastupanu vene võimule (King 2012: 80-83). Ometi kallutas pikk ja verine Kaukaasia sõda ning imaam Šamili juhitud vastupanuliikumine 19. sajandil abhaase tugevamini islami poole. Vene tsaarivõim kuulutas Kaukaasia sõja piduliku paraadiga Krasnaja Poljanas (hiljem eesti asunike poolt tuntud Punase Lagedana) lõppenuks küll 1864. aastal, kuid vastupanu jätkus eriti just Abhaasias ka järgmistel aastatel. Tsaarivõimu allergia moslemite suhtes sünnitas ridamisi piiranguid Abhaasia moslemitele: neil keelati abielluda kristlastega, panna lastele moslemi nimesid, matta lahkunuid moslemi kombel, keelati mullade tegevus ja suleti mošeed. Islamiusulisi lapsi ei võetud kooli, moslemitel keelati teatud elualadel tegutsemine ja relvakandmine (Tsakvetadze 2009: 89). Mitme lainena küüditati abhaase nende põlistelt asualadelt Türgisse. Täpset arvu on täna võimatu öelda, ${ }^{6}$ kuid erinevail hinnanguil lahkus 1860.-1870. aastatel Türgisse 120000 - 200000 abhaasi (Geldenhuys 2009: 70). Ühtekokku deporteerisid tsaarivõimud pool kuni kolm neljandikku abhaasidest nende ajalooliselt kodumaalt. Mahadžirid (pagulased) - see on mõiste, mis Abhaasias on laetud samasuguse pingega nagu Eestis küüditatud või sõjapõgenikud. Küüditamiste (mahadžirun) üks eesmärk oli tsaaririigi piirialade puhastamine "vaenulikust elemendist" (Khorava 2011: 346), st moslemitest. ${ }^{7}$ Kirjanduses kohtab väiteid, et küüditamised ei puudutanud üldiselt kristlastest abhaase (Khorava 2011: 347). See väide on eksitav - on teada juhtumeid, kus Türgisse küüditatud kristlastest abhaasid kannatasid Türgis usulise rõhumise all, üritasid oma kodumaale tagasi pöörduda, kuid saadeti sadamatest Türgisse tagasi (Argun 2014: 77; Gadnani \& Džakeli 2006: 
109). See fakt näitab, et mahadžirun ei toimunud üksnes religioossetel alustel, kuigi tsaarivõim seda niimoodi esitas.

Pärast mahadžiride maalt väljaajamist oli tsaarivõim kindel, et kohalikud õnnestub "tsiviliseerida" ja levitada nende seas ristiusku. Õnnestuski, sest rahvas oli seatud küsimuse ette - olla või mitte olla. Ristiusku pöördumist soodustas ka asjaolu, et maal olid säilinud kirikud - Abhaasia oli olnud ju sajandeid kristlik maa. Ka lootsid abhaasid, et ristiusku pöördumine aitab neil tõusta tsaarivõimude silmis paremasse valgusse ja neil õnnestub säilitada oma maavaldused. Ainuüksi 1877. aastal astus õigeusku 21336 abhaasi, peaaegu igal aastal küündis vastristitute arv 8000-ni (Kvitsinija 2012: 186).

Kuid selline ristiusustamine oli suuresti formaalne. Veel 1860. aastateks ei olnud ühegi sealse mägilasrahva keelde tõlgitud evangeeliume, kogu piiblist rääkimata. Sellest poleks ka palju kasu olnud, sest mägilased olid valdavalt kirjaoskamatud. Varasem sünkretistlik maailmapilt püsis jätkuvalt. Näitena lihtrahva sünkretistliku suhtumise kohta võib tuua juhtumi septembrist 1868, mil Abhaasias Pitsundas kavandas kohalike elanike ristimist misjonär Gona Geromonahh. Ta informeeris ametnikke Tiflisis, et küla oli ristimiseks ette valmistatud, siis aga teatasid kohalikud talle, et ta "annaks neile teada, millal on aeg, ja siis nad toovad tseremoonia jaoks kana ja veini" (Jersild 2000: 520-521). Abhaasi usu rituaalide läbiviimine eeldab kindlasti ka loomohvrit ja ühist rituaalsöömingut koos veinijoomisega (Tsakvetadze 2009: 58).

Ristiusustamine abhaase ei päästnud. Abhaasiasse alles jäänud abhaasidel keelati elada rannikupiirkonnas ning lähemal kui 20 versta pealinnast Suhhumist. Küüditamiste ja ümberasustamistega seostus riigi soov asustada vabanenud maadele riigitruid ja "tsiviliseeritud" kodanikke muudest provintsidest - see kõik näitab, kui silmakirjalik oli Vene võimude imperialistliku ekspansiooni õigustamine kristianiseerimise vajadusega. Eelisõigust maad saada pakuti õigeusklikele vene talupoegadele. Ka nn kloostrikolonisatsioon pidi aitama nii maad venestada kui ka ristiusustada - 1872. aastal asutati Pitsundasse vene klooster. 1874. aastal rajati Uus-Athose Siimon Kananaiose klooster Psirtskhasse, Suhhumist umbes $50 \mathrm{~km}$ mööda rannikut põhja poole paika, kus pärimuse järgi umbes aastal 55 oli Siimon Kananaios märtrina risti löödud ja maetud ning kuhu tema mälestuseks oli 4. sajandil ehitatud väike puust kirik, 7.-8. sajandil kivist kirik. Uus-Athose klooster oli Athose Püha Pantheleimoni vene kloosri filiaal. Hiljem rajati veel mitu kloostrit näiteks Dranda klooster Kodori jõe ääres 1885. aastal. Kõikidele neile jagati ka maavaldusi (Dzidzarija 1975: 434; Gelenava 2011: 254; Tsakvetadze 2009: 65; Akhaladze 2016: 71). 

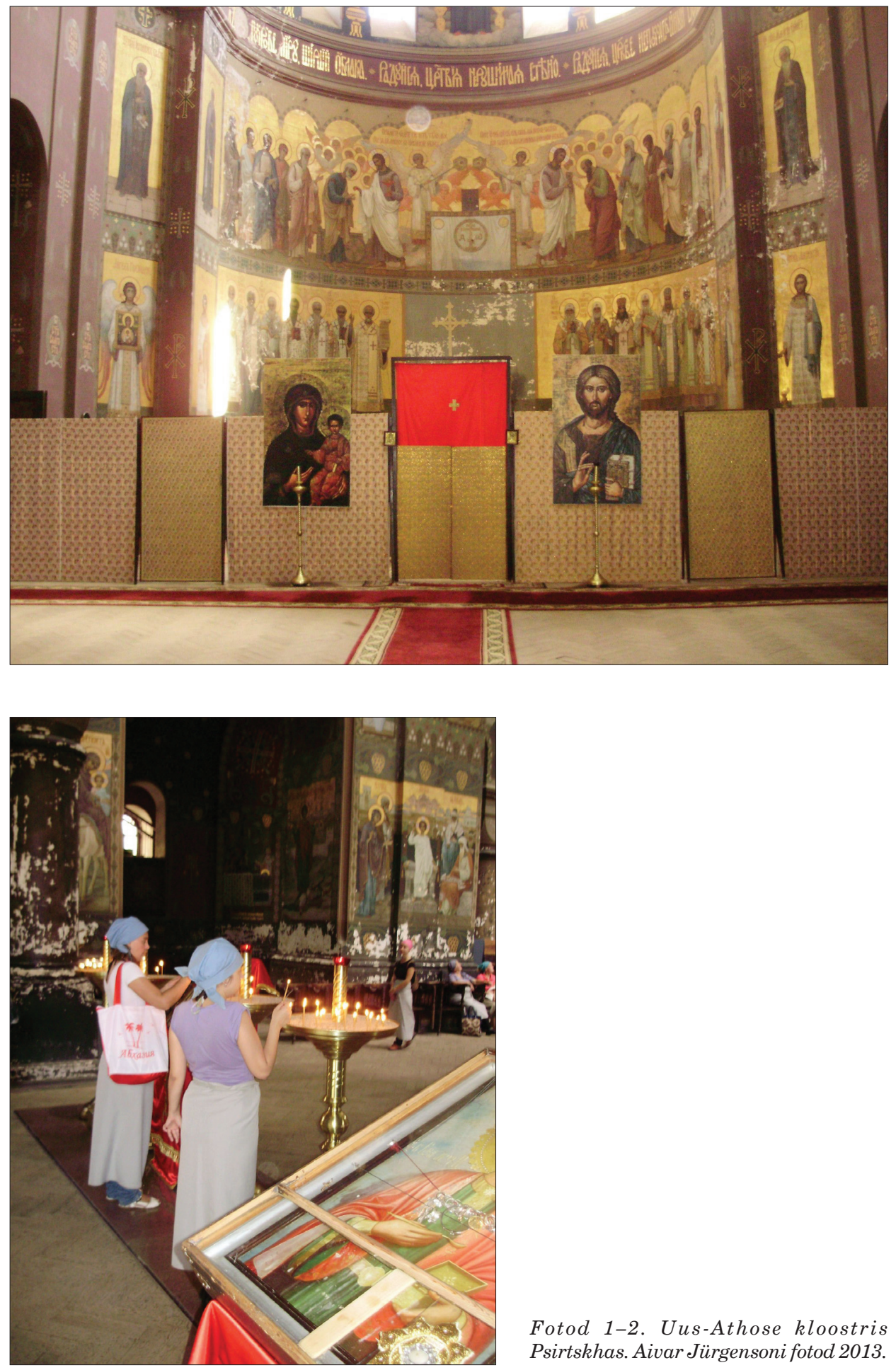

Fotod 1-2. Uus-Athose kloostris Psirtskhas. Aivar Jürgensoni fotod 2013. 
Niisiis Abhaasia religioosse maastiku arengud, mida mitmed autorid on nimetanud sünkretistlikeks, said 19. sajandi teisel poolel n-ö tagasikäigu. Vene võimude koloniaalne ekspansioon, mille ideoloogiliseks mootoriks ja tegelike ambitsioonide kattevarjuks oli kristluse "tagasitoomine" Abhaasiasse, asus juba aset leidnud sünkretistlike protsesside tagasipööramisele, n-ö antisünkretistlikule pealetungile. Kristluse purism vastandus eelkõige islamile - nagu on sedastatud Vene imperiaalse religioonipoliitika kohta üldistavalt, ei pidanud see šamanismi, paganlust, animismi jt religioosseid praktikad riigi ääremaadel impeeriumile nii ohtlikeks kui islamit (Jersild 2000: 527). Seega tõrjuti välja islam, pagendati moslemid ja järgnenud kolonisatsiooni käigus muudeti drastiliselt ka Abhaasia demograafilist olukorda.

\section{Abhaasia usuelu nõukogude ajal ja pärast seda}

Arenguid Abhaasia religioossel maastikul pärast 1917. aasta oktoobripööret saab käsitleda ateistliku sekulariseerimise võtmes. Kui seni tähendas mõne religiooni (antud juhul islami) survestamine teise religiooni (antud juhul õigeusu) dominantsed diktaati, siis enamlased kuulutasid kõik religioonid ühtviisi kahjulikuks ja võõrandumise ühest, teisest, kolmandast jne religioonist samaväärselt kasulikuks. Dekreediga 23. jaanuarist 1918 võõrandasid bolševikud kirikute vara ja keelasid usuõpetuse kõikides avalikes ja erakoolides. Vanem põlvkond pidi oma "religioossete eelarvamustega" välja surema ja andma teed ateistlikule noorsoole. Vaimulikud lahterdati "kõikide konfessioonide usukultuste teenritena" mittetöötava elemendi hulka, neilt võeti ära valimisõigus, samas maksustati nad kõrgeima maksumääraga, mida suudeti tasuda vaid koguduseliikmete abil. Abhaasiasse jõudis nõukogude võim 1921. aasta kevadel ja hakkas hoogsalt uut korda ehitama ka seal. Usuühenduste tegevust reguleeriv seadus 8. aprillist 1929 nägi ette tervet rida karistusi. Toimingud, mida riik pidas endale ohtlikuks, võisid kaasa tuua vangistuse või sunnitöö: rahvuslik või religioosne agitatsioon, lastele ja alaealistele usuõpetuse jagamine, kontrrevolutsiooniline ja valitsusvastane propaganda, kirikuvara varjamine jne. 1928. aasta jõulude eel leidis aset jõuludevastane kampaania, mis järgnevatel aastatel võttis üha äärmuslikumaid vorme. Usuvastane surve muutus tugevamaks ka koolis. Lapsed ja noored ei pidanud üksnes omandama marksistlikku maailmavaadet, vaid ka innukust võitluses usu vastu väljaspool kooli, sh kodus. Koolidesse saadetud inspektorid pidid lastele ootamatuid küsimusi esitades välja selgitama, kui palju neid kodus usuliselt mõjutatakse ja kasvatatakse (Roemmich 1978: 34, 35, 41). 1930. aastate teisel poolel leidsid aset vaimulike vahistamised kogu Nõukogude Liidus, sõltumata uskkonnast (Stumpp 1978: 
117). Abhaasias olid neil aastail põlu all nii õigeusk, abhaasi usk kui ka islam, samuti peamiselt eesti ja saksa asunike poolt viljeldud luterlus ning peamiselt poolakatele toetunud katoliiklus. Kui veel 1920. aastate teisel poolel tegutsesid kohati moslemi koolid, siis hiljem need suleti. Mullade tegevus oli keelatud, kuigi salaja see siiski jätkus (Tsakvetadze 2009: 90).

1930. aastate repressioonides, mis tabasid tegelikult tervet Nõukogude Liitu, näevad abhaasi autorid kohalikke erijooni ja tõlgendavad neid grusiinistamise võtmes. 1930. aastatel represseeriti peaaegu kõik mittegrusiinidest vaimulikud ja kirikukirjanduse abhaasi keelde tõlkijad - abhaasi autorite silmis oli repressioonide üheks tulemuseks Suhhum-Abhaasia piiskopkonna grusiinistumine (Tsakvetadze 2009: 66-67).

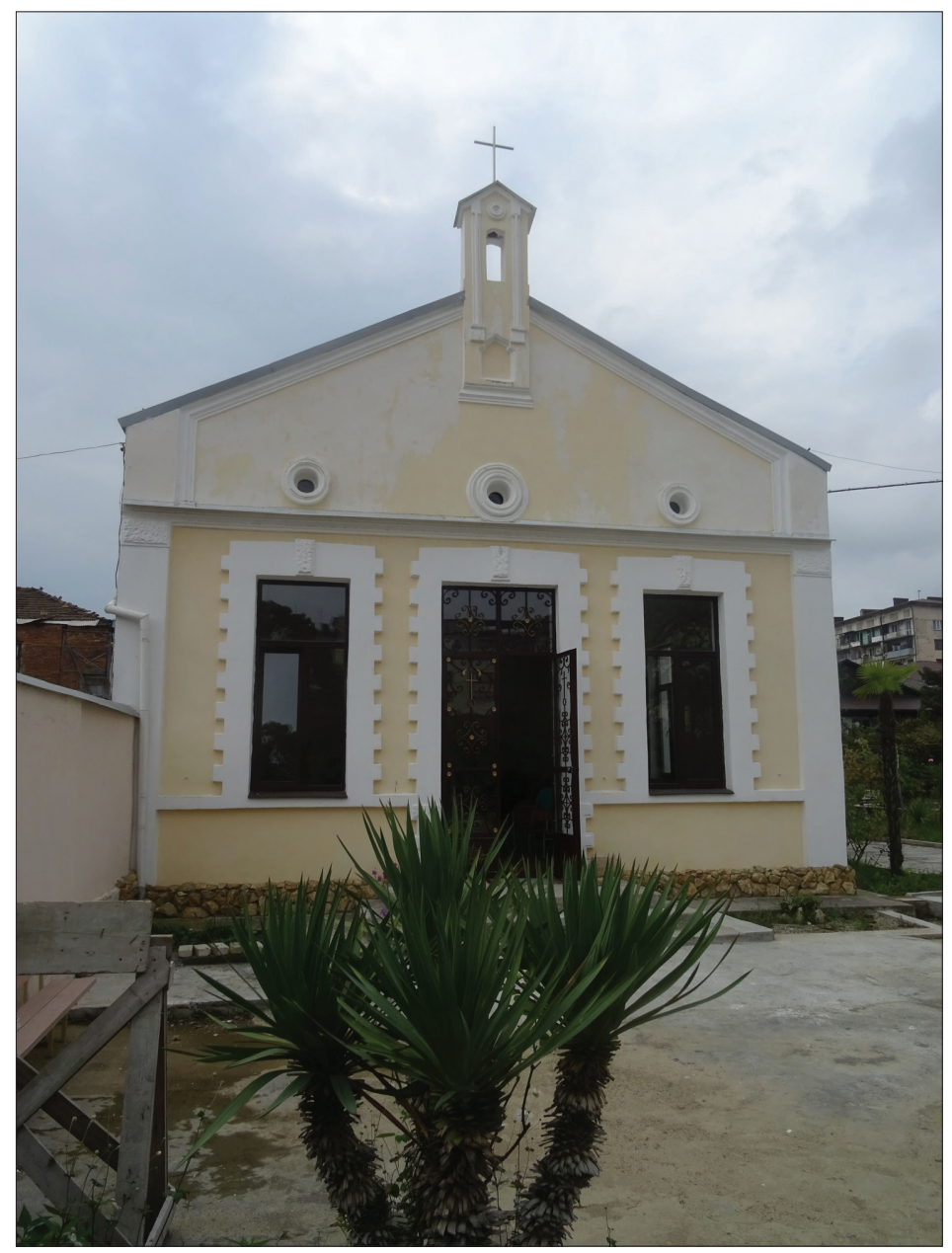

Foto 3. Siimon Kananaiose katoliku kirik Suhhumis. Aivar Jürgensoni foto 2016. 


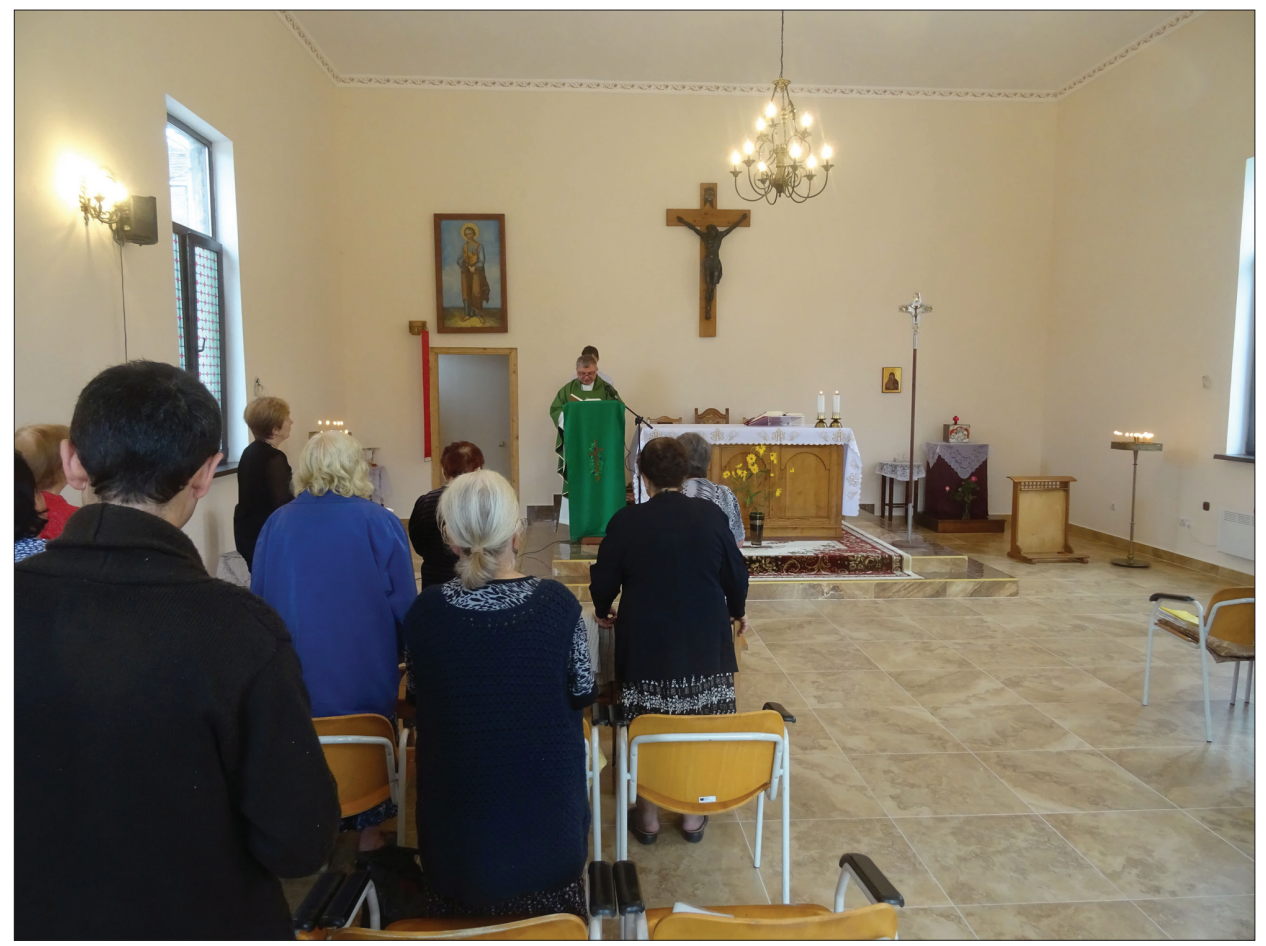

Foto 4. Missa Suhhumis katoliku kirikus. Aivar Jürgensoni foto 2016.

1980. aastate teise poole vabamates oludes jõudis Abhaasiasse mitmeid uusi usulisi liikumisi, millest aktiivseimaks osutusid jehoovatunnistajad. 1992. aastaks oli jehoovatunnistajaid Abhaasias 6000, neist Suhhumis 3000. Hiljem, aastal 2005 keelustas tollane Abhaasia president Vladislav Ardzõnba jehoovatunnistajate tegevuse Abhaasias, viidates põhiseadusele, mis keelab riigis tegutseda ühiskondlikel liikumistel ja parteidel, mille tegevus ja eesmärgid ohustavad riigi julgeolekut. Jõuti jehoovatunnistajate arreteerimisteni. Õigeusu kirik tervitas keeldu, samas väljendasid paljud intelligentsi esindajad keelu suhtes kriitilist suhtumist (Tsakvetadze 2009: 146-153; Ešba 2012: 8). Samas ei ole Abhaasias jehoovatunnistajate liikumise väljajuurimist võetud kuigi järjekindlalt ja nii on nad seal poolsalaja oma tegutsemist jätkanud. nõukogude ajal arhiivina tegutsenud evangeelse luteriusu Jaani kirik, mille tegevust koordineerib Taga-Kaukaasia Tbilisis resideeruv piiskop, avati taas 2003. aastal. Koguduses on 30-40 liiget, peamiselt sakslased. Katoliku kirik, mis oli Suhhumis avatud 1908. aastal ja 1937. aastal suletud, anti pärast Gruusia-Abhaasia sõda katoliiklastele tagasi. 1996. aastal avati kiriku juures 
pühapäevakool. Koguduse liikmed on peamiselt armeenlased ja poolakad (Ešba 2012: 12-13). Kiriku juures toimuvad ka poola keele tunnid. Katoliiklasi on Abhaasias üle kahesaja (Tsakvetadze 2009: 114-116).

Gruusia-Abhaasia konflikt räsis Abhaasias tegutsenud kirikutest ilmselt kõige enam õigeusukirikut - siin olid suhted kõige politiseeritumad. Juba 20. sajandi algul üritas tsaarivõim eraldada Abhaasia õigeusukirikut Gruusia omast (Gamakharia 2016: 38). Keerulistel kodusõja-aastatel soovis taas osa abhaasi õigeusu vaimulikest eralduda Gruusia õigeusukirikust, kuid Gruusia okupatsioon 1918. aastal tõmbas sellele kriipsu peale. 1919. aasta oktoobris Suhhumis korraldatud kirikukogu kinnitas Suhhum-Abhaasia piiskopkonna alluvuse Gruusia katolikosele (Papaskiri 2010: 207-208). Ka nõukogude ajal oli kirik allutatud Gruusia õigeusukirikule, 1930. aastate repressioonid tähendasid ka kiriku grusiinistumist. Nõukogude Liidu lõpuaastail tegutses Abhaasias kuus õigeusukirikut, kõik gruusiakeelsed. Ammu olid suletud viis varem tegutsenud kloostrit (Tskavetadze 2009: 72).

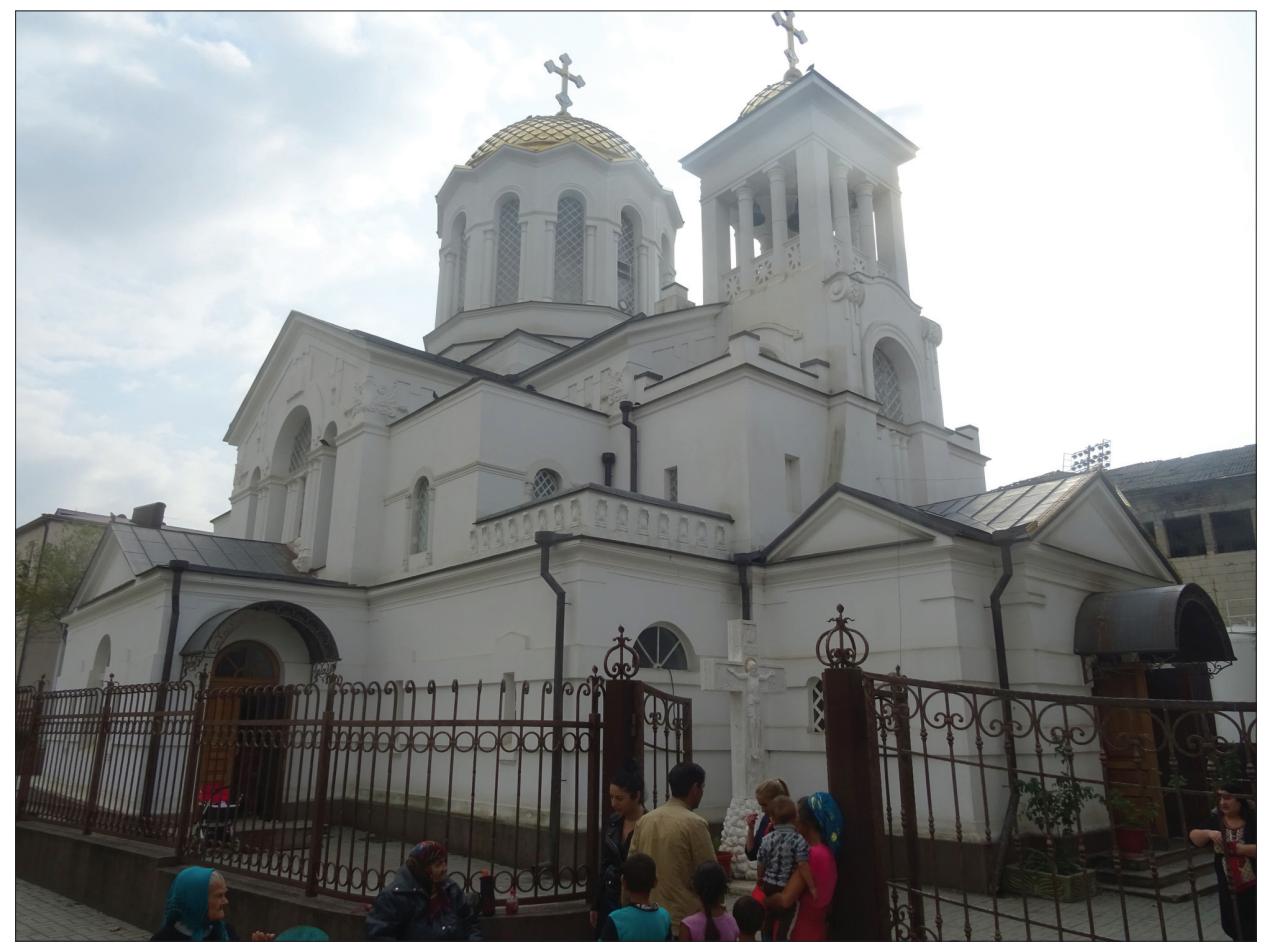

Foto 5. Õigeusu katedraal Suhhumis. Aivar Jürgensoni foto 2016. 


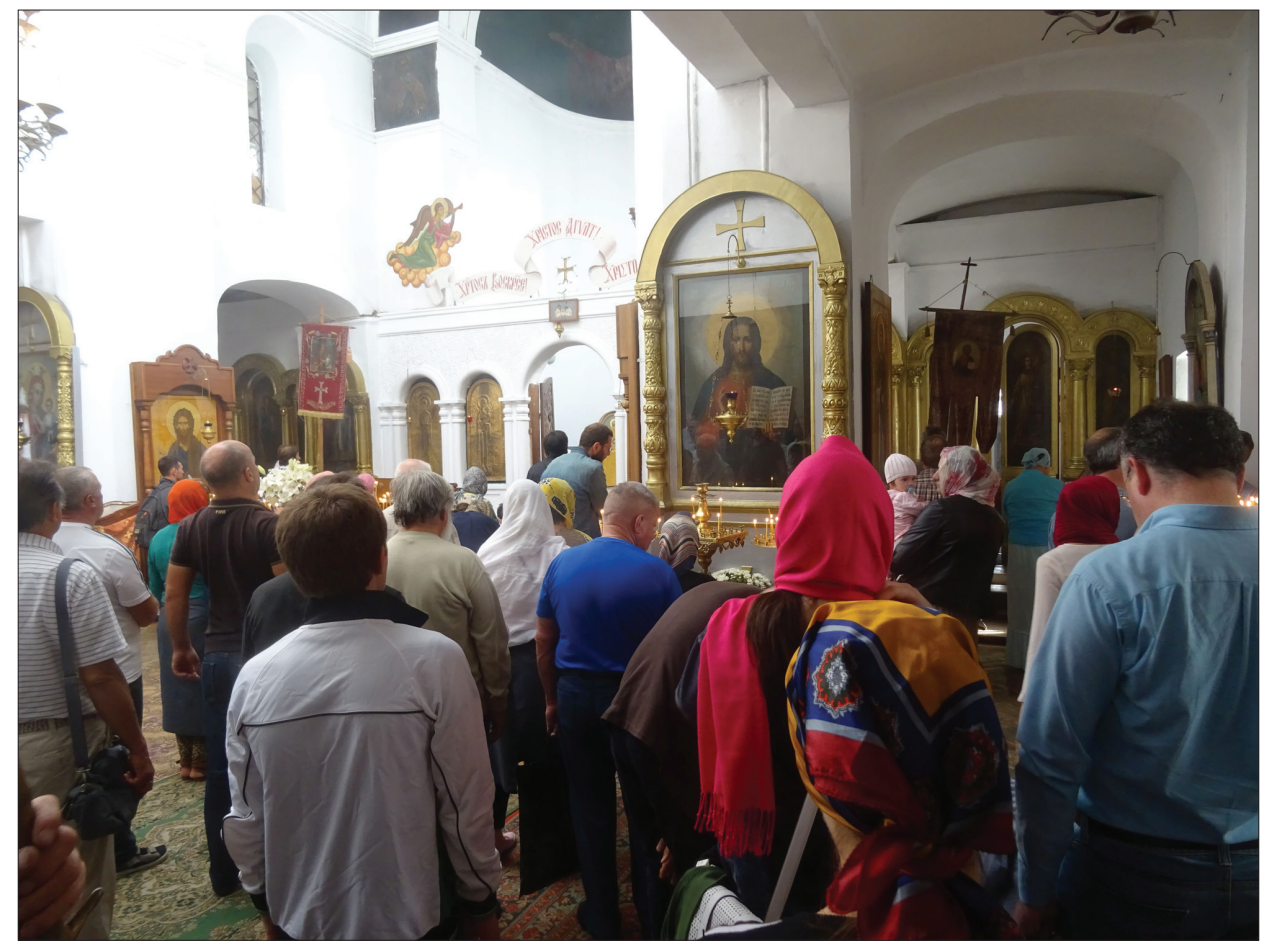

Foto 6. Jumalateenistus Suhhumis õigeusu katedraalis. Aivar Jürgensoni foto 2016.

Kui 1992. aastal puhkes sõjategevus, olevat Abhaasia õigeusu metropoliit David tervitanud grusiinide sissetungi. Kui sai selgeks, et grusiinid sõja kaotavad, pagesid gruusiameelsed õigeusu vaimulikud Gruusiasse. Tänaseni tegutseb Gruusias Suhhumi-Abhaasia piiskop, kuigi ilma sisulise võimaluseta koordineerida vaimulikku tegevust Abhaasias. Teenistusi peetakse kirikus nüüd gruusia keele asemel kirikuslaavi ja abhaasi keeles (Tsakvetadze 2009: 67, 78). Abhaasi õigeusukiriku piiskopkonna ajutine nõukogu ei tunnista Gruusia kiriku ülemvõimu. Tulemuseks on, et paljudes Abhaasias asuvates õigeusukirikutes pole vaimulikke (Ešba 2012: 11). Abhaasi kleerikud on otsinud nii Moskvast kui ka Konstantinoopolist toetust kiriku eraldumisele Gruusia õigeusukirikust. Kuid nii nagu Abhaasia riikliku iseseisvuse tunnustamisega, on lood ka tema õigeusukirikuga - isolatsioonist on raske väljuda.

Kuigi Abhaasia territooriumil on umbes 400 õigeusukirikut, ehitatud erinevatel aegadel alates neljandast sajandist, seisab suurem osa neist tühjana, paljud on varemetes. Suhhumi-Abhaasia piiskopkonnas tegutseb tänapäeval 24 kirikut, lisaks kaks mungakloostrit: Püha Siimon Kananaiose klooster Uus- 
Athoses ja Püha Johannes Kuldsuu klooster Kamanõ asulas (Tsakvetadze 2009: 73; Ešba 2012: 9). 2002. aastast tegutseb Baslata asulas Suhhumi rajoonis naisklooster mõnekümne nunnaga. 2002. aasta septembris avati Uus-Athose Piiskoplik Vaimulik seminar (Tsakvetadze 2009: 78, 83).

Õigeusukirikuga seoses tuleb rääkida ka palveränduritest-erakutest, kelle vaimsete otsingute sihtkohaks ja elupaigaks on Abhaasia olnud sajandeid. Aastatel 2001-2005 registreeriti Abhaasias 24 mägedes elavat vaimulikku erakut, peamiselt Pšu asula ja Amtkeli järve piirkonnas. Ametlikult registreeritud erakute kõrval on aga palju selliseid, kes elavad varjatult mägedes ja metsades - nendest ülevaade tegelikult puudub. Mõned erakud on varjulistes paikades elanud mitukümmend aastat, enamasti pühapaikade läheduses: UusAthose klooster, Kamani klooster, Iveri mägi, apostel Siimon Kananaiose koobas, kirikud Akapa, Guma jt asulates. Ka leidub hooajaliselt rändavaid munki ja erakuid, kes tulevad Venemaalt, Ukrainast, Valgevenest jm suveperioodiks (Tsakvetadze 2009: 81-83).

Kui rääkida islamist tänapäeva Abhaasias, siis on sellele räsivalt mõjunud tsaariaegsed küüditamised ja nõukogudeaegsed tagakiusamised. Suurel osal neist, kes tänapäeval end moslemiteks peavad (10-20\% elanikkonnast), on islami põhimõtetest vaid pealiskaudsed teadmised. Islami ettekirjutusi rangelt ei järgita (Ešba 2012: 11; Tsakvetadze 2009: 91).

Aleksandr Krõlov märgib, et “abhaasid, kes peavad end muhameedlasteks, ei loe prohvet Muhamedi, suuremal osal ei ole mingit ettekujutust Koraanist ega tunne nad mingit huvi selle uurimise vastu. Mitte ükski meie küsitletud "abhaasi muhameedlastest" ei teadnud midagi viis korda päevas palvetamisest..." (Krõlov 2001: 65, tsit Broido 2010: 65). Anna Broido kirjutab, et kristlased on tähistanud koos moslemitega moslemi pühasid ja vastupidi. Samuti esitab ta oma raamatus värvika juhtumi, kuidas ühes abhaasi peres näidati ajaloolasele perekonna reliikviat, surnud isa Koraani. Isa peeti mitte üksnes moslemiks, vaid koguni mullaks. Tähelepanelikumal vaatlusel selgus aga, et nimetatud "Koraan" on hoopis evangeelium, välja antud 20. sajandi alguses abhaasi keeles, mida tollal kirjutati ladina tähtedega (Broido 2010: 65). Neid seiku esitab Anna Broido religioosse sünkretismi näidetena, kuid teades islami kallal teostatud vägivalda tsaarivõimude poolt ja hilisemat ateistlikku pealetungi, sobiksid need näited illustreerima pigem sekulariseerimisprotsesse - enamik abhaasidest moslemeid küüditati tsaariajal Türgisse, nõukogude aeg surus selle vähese islami, mis veel säilinud oli, põranda alla. Pereringis edasi kantud islami tavade järgimist ei saa võrdsustada sügava islamireligioossusega. Sekulariseerumist ja sünkretismi pole aga põhjust samastada - religioossetes arengutes on need paralleelsed, kuid mitte kattuvad teed. 


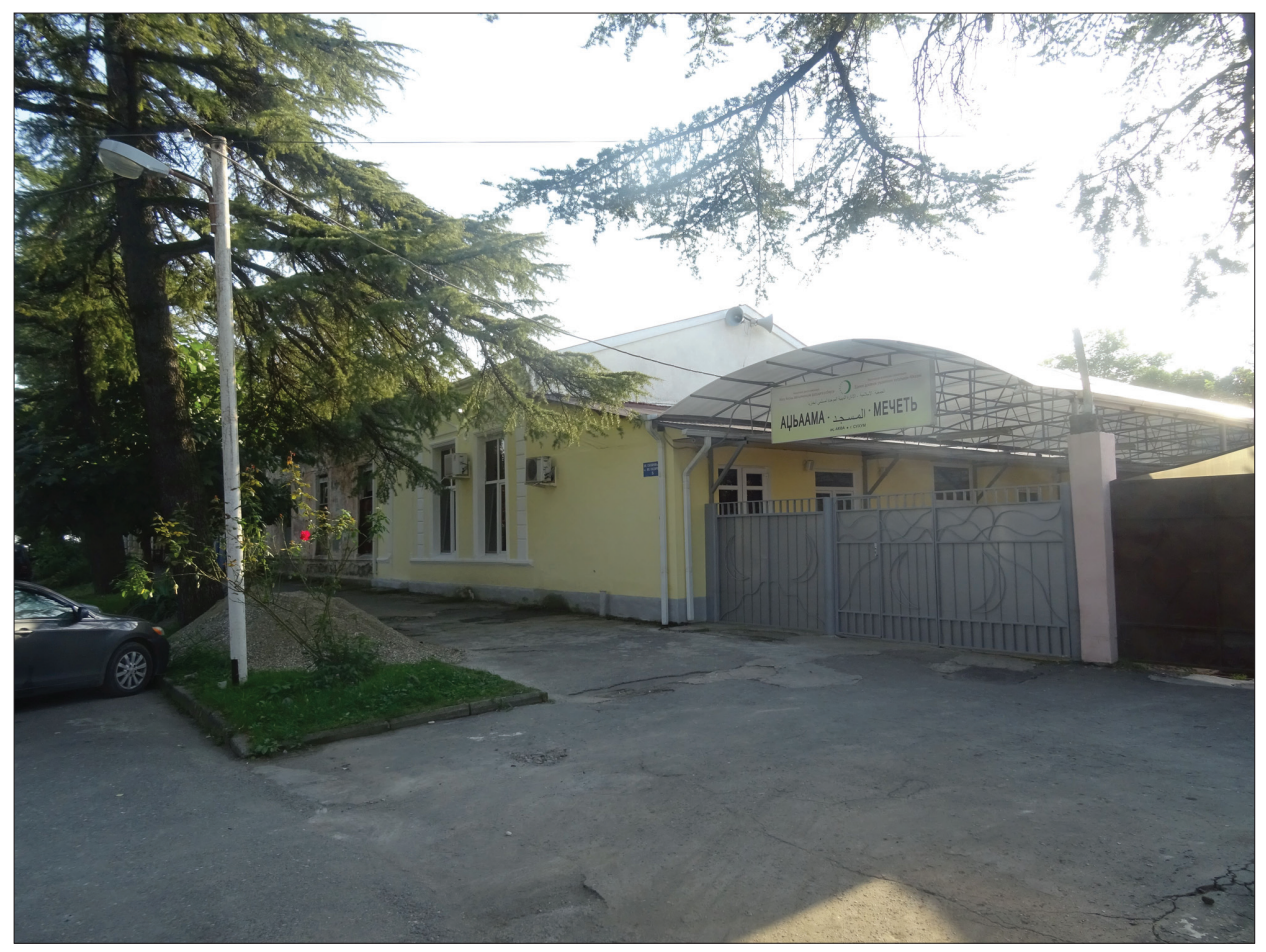

Foto 7. Moslemi palvemaja Suhhumis. Aivar Jürgensoni foto 2016.

21. sajandil on Abhaasias siiski täheldatav teatav islami tõus, seda seoses abhaasia repatriantidega Lähis-Idast ja muude immigrantidega. Tänapäeval moodustavad abhaasid (koos repatriantidega) Abhaasia moslemitest vaid $25 \%$. Umbes $35 \%$ on põhjakaukaaslased, ülejäänud tatarlased, baškiirid, Kesk-Aasia rahvaste esindajad ja türklased. Suur osa saabujatest on tõsiusklikud moslemid. Ühtki mošeed aga Abhaasias praegu ei tegutse, küll töötab kaks palvemaja - üks Suhhumis ja teine Gudautas. Samas on Venemaa muftide nõukogu, Tšetšeenia, Saudi-Araabia ja Türgi avaldanud valmisolekut toetada Abhaasias mošee ehitamist (Ešba 2012: 11).

Käsitledes abhaasi repatriantide ja teiste moslemite saabumist Abhaasiasse on nii abhaasi kui ka eriti gruusia autorid hakanud rääkima islami fundamentalismi ohust (Lakoba 2000: 112; Gadnani \& Džakeli 2006: 85). Eelkõige on taustaks vahabismi mõju suurenemine kogu regioonis, sh Gruusias - viimases eksisteerivad tänaseni moslemi enamusega või suure osakaaluga kistide, adžaaride, avaaride ja aserite piirkonnad. Täna näib siiski, et islami fundamentalismi aktuaalsusest saab rääkida pigem seoses nimetatud Gruusia piirkondade 
ja mitte Abhaasiaga. Aktiivne moslemikogukond, kes regulaarselt külastab palvekodasid, ei ole Abhaasias suurem kui paarsada inimest. Ja nagu eespool sedastatud, pole Abhaasia põlismaise islami rahvastiku maailmavaade kindlasti fundamentalistlik.

\section{Kristlikud moslemipaganad - sünkretismist ja sekulaarsusest Abhaasia religioonis}

Artikli alguses viitasin autoritele, kelle meelest on Abhaasia hea näide maast, kus kristlus ja islam on sajandeid rahumeelselt kõrvuti eksisteerinud ja kus on ruumi jäetud ka põlisele loodususule. Abhaasia etnoloog Teimuraz Atšugba leiab, et sajandite jooksul on abhaasidel välja kujunenud tolerantsus nii traditsioonilise loodususu kandjate kui monoteistide, st kristlaste ja moslemite suhtes. Atšugba väitel on abhaase nimetanud "kristlikeks moslemipaganateks" (Atšugba 2011b: 220).

Kui rääkida abhaasi autoritest, siis on huvitav, et just sünkretismi ja oma animistliku loodususu ning mitte islami kaudu rõhutavad nad abhaaside vaimset sidet Põhja-Kaukaasia rahvastega. Igatahes on abhaasi autorid oma maa elanike usulisest koosseisust kirjutades toonud esiplaanile paganluse ja õigeusu, kohati ka katoliikluse ja jätnud islami parimal juhul kolmandale positsioonile (Lakoba 2004: 9). Vähemalt osaliselt annavad sellisele valikule vastuse 20. sajandi ja eelkõige 1990. aastate poliitilised konfliktid - argumenteeritakse eelkõige grusiinide väidete vastu, mille kohaselt oli tollane sõda ususõda kristlaste ja moslemite vahel.

Rahvusromantilist usulist idülli leiavad tänased abhaasi autorid varasemate kirjutistest, kuid toodavad seda ka ise jätkuvalt edasi. Võiks ju kriitiliselt küsida, kas ristiusustamises ja hilisemas islamiseerimises võib leida mingeid asjaolusid, mis võimaldasid varasematel religioonidel suuremate kadudeta edasi püsida? Nagu eespool öeldud, jõudis kristlus Abhaasiasse juba meie ajaarvamise esimestel sajanditel ja sai ametlikuks usuks 6.-7. sajandil. Kuivõrd protsess pole täpselt teada, kohtab abhaasi autorite kirjutistes erinevaid spekulatsioone. Näiteks G. V. Smõr, esindades evolutsionistlikku suunda, kirjutab, et abhaasid olid esimestel sajanditel jõudnud vaimsesse valmisolekusse võtta vastu senisest universaalsem religioon kristluse näol (Smõr 1994: 6). Kui Smõri seletusega mitte leppida, tuleks otsida väliseid - poliitilisi, sotsiaalseid vms põhjuseid. Nõukogudeaegne autor Zurab Antšabadze oletas, et ristiusku pöördumise taga oli abhaaside soov pääseda ristiusulise Ida-Rooma keisririigi võimude tagakiusamisest (Antšabadze 1976: 42). A. R. Gumba, kes idealiseerivalt kujutab omaaegset animistlikku usku inimese ja looduse vahelise har- 
mooniana, mille peamisteks väärtusteks on vabadus ja armastus looduse vastu, leiab, et vabadustarmastavale abhaasile ei saanud kristluse käsitlus inimesest kui patusest olevusest südame järele olla - ja kuna kristliku ning omaaegse loodususu maailmavaate vahel valitsesid ideoloogilised vastuolud, pidi kristlus olema abhaasidele mujalt peale surutud. Gumba kasutab tänulikult ära Antšabadze nõukogudeaegse seletuse (Gumba 2011: 324). Huvitav on Mihhail Gunba seisukoht. Kui tavaliselt eeldatakse, et uue religiooni võtavad esmalt vastu valitsevad ringkonnad, siis tema on arvanud, et Abhaasias oli uuele ideoloogiale altim lihtrahvas ja vastupanu võisid osutada hoopis valitsevad kihid, sest just sealt pärinesid abhaasi loodususu preestrid (Gunba 1989: 82).

Mis aga tingis selle, et kristluse tulles jäi kohalik abhaasi usk siiski läbi sajandite püsima? Ja miks ei surunud hiljem saabunud islam välja ei kristlust ega abhaasi usku? Ja miks ei ole abhaaside hulgas fanaatilisi kristlasi või moslemeid? A. R. Gumba näeb võtit apsuara's - abhaasi traditsiooniliste teadmiste, maailmatunnetuse, eetika, vaimsete väärtuste ja au koodeksis. Ta leiab, et see koodeks on abhaaside teadvuses nii sügavalt juurdunud, et aja jooksul allutati sellele ka religioon, mis võis varem olla olulisemal positsioonil. Aukoodeks apsuara reguleeris kohalikku elu nii tugevalt, et ei jätnud võimalust usutülideks (Gumba 2011: 321-325). Kui Gumbal peaks olema õigus ja maist elu reguleeriv aukoodeks on aegade jooksul tõrjunud religioossed ideed sekundaarsele positsioonile, võis see kaasa aidata ka sünkretistlikele arengutele abhaaside maailmapildis. Ka Teimuraz Atšugba on juhtinud tähelepanu apsuara rollile abhaasi usulise maailmavaate kujunemisel (Atšugba 2011b: 221). Kui abhaasi religiooniloo uurija Gulnara Tsakvetadze kirjutab apsuara läbipõimumisest suurte usundite maailmapildiga (Tsakvetadze 2009: 66), siis viitab ka see sünkretistlikele arengutele.

Nõukogude ajal olid Abhaasias põlu all kõik religioonid. Kristlikud ja moslemi sakraalhooned olid suuremas osas suletud, abhaasi loodususu ohverdused pühapaikades keelatud ja karistatavad. Kuid salaja täideti nii kristlikke, islami kui ka loodususu traditsioone. On teada, et 1931. aastal, mil Abhaasias leidis aset kollektiviseerimine, võeti ühel suurel abhaasi talupoegade koosolekul vastu otsus kolhoosi mitte astuda. Selle otsuse kinnitamiseks tõusti Dõdripš-Nõha mäele, abhaasi jumaluse pühapaika, kus anti tõotus sellele otsusele kindlaks jääda. Kuid edasiste repressioonide käigus viidi kollektiviseerimine Abhaasias ikkagi ellu (Tsakvetadze 2009: 56).

Dõdripši mäel käidi palvetamas ka näiteks Gruusia-Abhaasia sõja ajal 1992-1993. Inimesed olevat tõlgendanud sõda oma usu jumalatest kaugenemise ja vaimsete juurte kaotamise tagajärjena. Sõda, sellele järgnenud majandusblokaad ja isolatsioon on mõningate autorite sõnul aidanud kaasa sellele, et inimesed on pöördunud tagasi oma traditsioonilise usu juurde (Tsakvetadze 2009: 61; Ešba 2012: 13). 


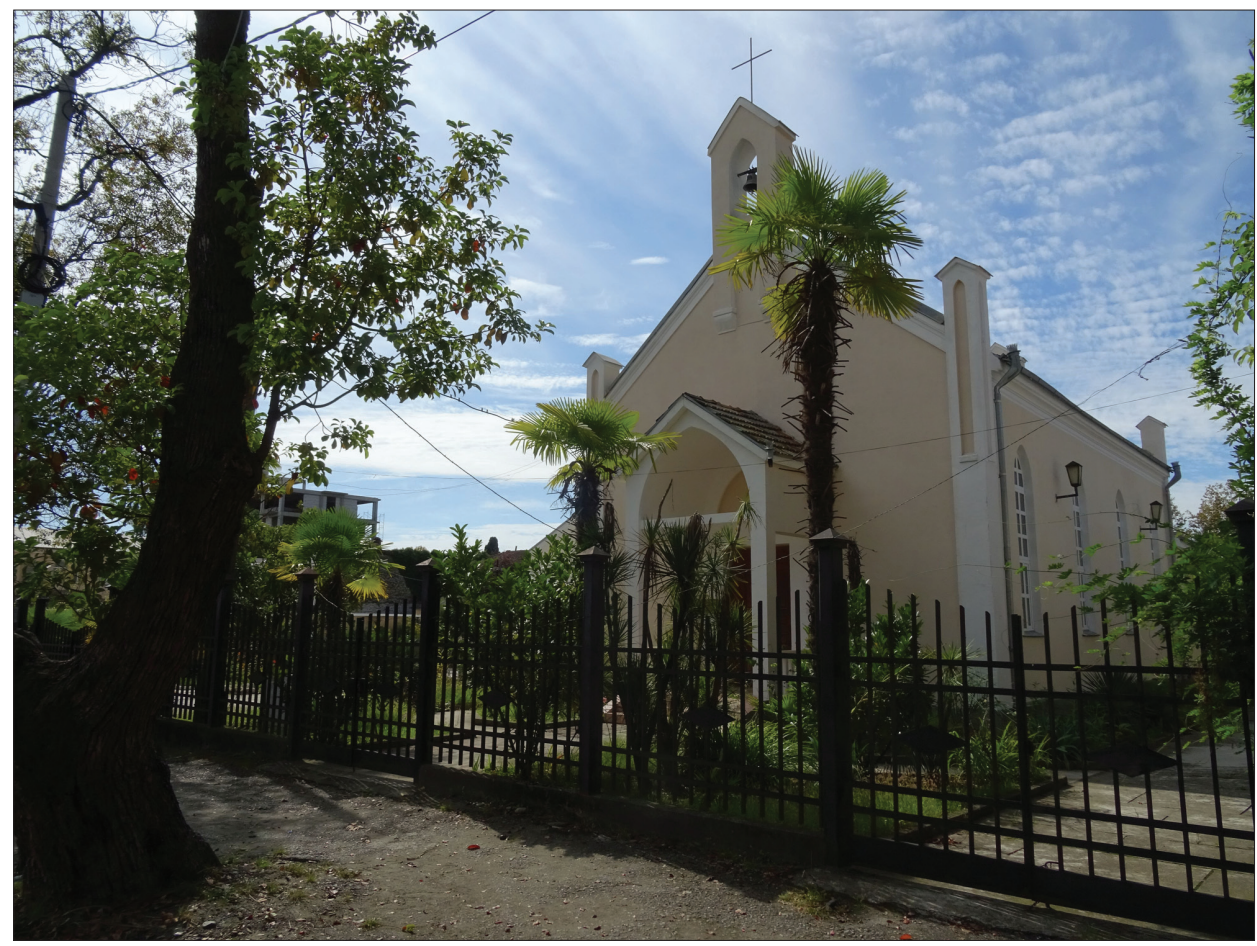

Foto 8. Luteriusu Johannese (Jaani) kirik Suhhumis. Aivar Jürgensoni foto 2018.

Pärast Gruusia-Abhaasia sõda on Abhaasia võimud toetanud abhaasi usku abhaasi identiteediloome instrumendina. Abhaasia presidendi Vladislav Ardzõnba inauguratsioontseremoonial 6. detsembril 1999 oli Abhaasia preestrite nõukogu esimehena kohal ka Zaur Tšitšba, Dõdripš-Nõha preester (Tsakvetadze 2009: $55)$.

Samas on Abhaasia elanikkonnast abhaasi usu järgijaid ametlikult vaid $3 \%$ elanikkonnast. Võrdluseks: kristlasi on $60 \%$, moslemeid $16 \%$. Enamus on seega kristlased, kuid tasub märkida, et vaid vähesed käivad teenistustel ja loevad pühakirja. Sama võib öelda muhameedlaste kohta. Usuline kuuluvus on pigem formaalne (Ešba 2012: 13). Kui sellisel foonil on Abhaasia riik hakanud taaselustama traditsioonilist abhaasi usku ja läbi viima tseremooniaid, siis on sellel eelkõige rahvust konsolideeriv ja identifitseeriv funktsioon.

Nägime, et mitmed autorid on Abhaasia religioosse situatsiooni puhul rääkinud sünkretistlikest arengutest ja fundamentalismi puudumisest. Nn raamatureligioonide kristluse ja islami fundamentalismi puudumise põhjustest oli eespool juttu, kui aga rääkida abhaaside maailmapildi sünkretistlikkusest, siis 
eespool esitatud James Huntley Graysoni sünkretismi tüpoloogias paigutuks see nn madala sünkretismi vormi, kus nn maailmausundi(te) ja kohaliku usundi kokkupuutel lisandub kohalikku usundisse küll väliseid vorme ja pindmisi jooni, kuid kohaliku usundi tuumväärtused jäävad püsima. Üks põhjusi on ilmselt abhaaside tavaõigusliku apsuara tugev mõju abhaaside maailmapildile läbi sajandite. Kui aga rääkida mõistetest, mille kaudu abhaaside religioosset maailmapilti teaduslikult avada, leian, et sünkretismi kõrval tuleks tugevamini kaasata sekulariseerumise mõistet, vähemalt tänapäeva kontekstis. Tsaari-ja nõukogudeaegsed repressioonid religioonikandjate vastu ja nõukogudeaegne ateistliku maailmapildi juurutamine on religioossust Abhaasias vähendanud ja selle käigus religioonide piire hägustanud. Sekulaarsed protsessid on viinud huvitavate arenguteni. Abhaasi uurija Gulnara Tsakvetadze kirjutab, et kuna Abhaasias toetatakse igati just traditsioonilist abhaasi usku, võib see viia abhaaside oma usu unifitseerimiseni - ehk võib viimane tõusta isegi riigiusu staatusse (Tsakvetadze 2009: 62). Eespool esitatud statistika foonil, kus abhaasi usu tunnistajaid on riigi elanikkonnast vaid mõni protsent, võivad sellised arengud aset leida üksnes tugeva sekulaarsuse tingimustes, kus riigivõimu suunav käsi ei kohta teiste religioonide tunnistajate vastupanu.

Mitmed teadlased, kes ühelt poolt uurivad abhaasi religiooni, teiselt poolt aga panustavad ka ise aktiivselt identiteediloomesse, on väitnud, et abhaaside traditsiooniliste uskumuste vaimsed väärtused ei ole kristlusega vastuolus, vaid need pigem täiendavad üksteist (vt Ešba 2012: 13). See sünkretistlik-harmoniseeriv lähenemine on mõistetav Gruusia-Abhaasia vastuolude taustal. Nähtus pole iseenesest unikaalne. Maailmast võib leida palju näiteid selle kohta, kuidas koloniaalsetele võimudele vastanduvad rahvuslikud liikumised suhtuvad religioossete elementide segunemisse positiivselt - see on omamoodi vastupanu koloniaalsete metropolide arrogantsile või purismile (Stewart 1999: 54).

Sünkretistlikel arengutel võivad seega olla profaansed motiivid, Abhaasia näite puhul võime siin näha ka sünkretismi ja sekularismi komplementaarsust. Kohati teoloogias esindatud vaade, mille kohaselt sünkretism on oma olemuselt sekulaarne vastupidiselt tõelisele religioonile (vt Leopold \& Jensen 2014b: 15) võib küll ehk tunduda kategooriline, kuid teatud osa tõtt võib siin siiski olla. Abhaasia usuelus tänapäeval täheldatav religioossete elementide segunemine, erinevate uskude rituaalide vahelduv praktiseerimine, rahvuslike eliitide väited erinevate uskude omavahelisest harmooniast eesmärgiga rahvast konsolideerida - see kõik saab ladusamalt kulgeda mitte antisünkretistlikes, vaid sekulaarsetes tingimustes. 


\section{Kokkuvõte}

Artikli alguses viidatud autorite sõnumil Abhaasiast kui usulise tolerantsuse maast on palju tahke ja sellesse võib suhtuda mitmeti. Üheks oluliseks argumendiks peavad mitmed nähtust käsitlenud autorid apsuara, abhaasi tavaõigusliku eetikakoodeksi sajanditepikkust mõju, mis pole lasknud ühelgi kohapeal eksisteerinud religioonil saavutada kõikehõlmavat domineerimist abhaaside südametes. Samas võib usutülide puudumisel olla teisigi põhjusi, nii religioonipõhiseid kui ajaloolisi ja ka geograafilisi. Esiteks ei ole õigeusk, mis valitses Abhaasias peaaegu tuhat aastat (6.-15. sajand), ka mujal maailmas oma kanoonilistel territooriumidel paganlikke usukujutelmi lõpuni välja juurinud - mõelgem Eesti kontekstis kasvõi setudele. Teiseks võib rääkida füüsilistest barjääridest - kaugetes ligipääsmatutes mäestikuorgudes toimuv jäi usujuhtide pilgu alt suuresti välja. Nii oli see ka mujal Kaukaasias, ja see muutis piiri pealtnäha kristlaseks või pealtnäha moslemiks olemise vahel ebamääraseks (King 2012: 73). Mis puudutab islami ja kristluse vahekorda, siis polnud osmani valitsejatel oma riigi muu-usuliste islamiseerimine pragmaatilistel kaalutlustel prioriteet - muu-usulised täitsid maksudega riigikassat. Pealegi jäi islami domineerimise periood Abhaasias võrdlemisi lühikeseks. Mis puudutab abhaasi oma usu kujutelmade säilimist läbi sajandite kahe suure, islami ja kristluse kõrval, on sellelgi paralleele mujalt maailmast. Marid või näiteks udmurdid on oma paganlikke jooni säilitanud just kristluse ja islami kontaktaladel, kus kumbki suur religioon pole selget hegemooniat saavutanud.

Kui rääkida veel uskude rahumeelsest kooseksisteerimisest, siis nägime eelnevalt, et ristiusu uus tulemine Vene tsaaririigi teenistuses 19. sajandil oli vägagi vägivaldne ja religioosselt puristlik. Samas oli roll, mille Vene võimud ristiusule nüüd andsid, nii läbinähtavalt profaanne ja imperialistlik, pealegi oli kristlus Abhaasias sügavalt varemgi juurdunud, et ka sellelt pinnalt ei tekkinud põlisrahva seas suuri uskudevahelisi konflikte. Võimalik, et mahadžiruni, mitmete järjestikuste küüditamistega 19. sajandi teisel poolel neutraliseeriti islami fundamentalistlik suund Abhaasias. Siiski mõne autori hinnangul kaldumine islami poole abhaaside seas just sel ajal pigem kasvas - eelkõige siis vastureaktsioonina venestamisele. Kuid suuremaid vastuhakke usulisel pinnal enam ei järgnenud - tsaarivõimude brutaalsed meetodid olid oma mõju juba avaldanud. Kui ka oli neid, kes sel ajal islami poole kaldusid, nägime samas, kui palju oli neid, kes andsid võimudele järele ja pöördusid ristiusku. Kui osalt ka reageeriti protestiks välisele survele kaldumisega islami poole, siis sama võib öelda ka abhaasi omausu rituaalide täitmise kohta - ka nende poole pöörduti rasketel aegadel. Nii situatsioonist tulenev usuliste rituaalide täitmine kui ka usuvahetus välisel survel näib viitavat pigem fundamentalismi puudumisele 
või vähemalt vähesele mõjule. Kui nii, siis on mõistetav ka abhaaside maailmapildi avatus sünkretistlikele arengutele.

Kui tsaristlik usupoliitika oli oma olemuselt puristlik ühe uskkonna eelistamine teistele, siis hilisem nõukogudeaegne ateismi pealetung oli üheselt sekulaarne. Kõik uskkonnad kannatasid nõukogude võimu religioonivastaste repressioonide käes, sakraalhooned olid suletud, teenistused jm religioossed kombetäitmised keelatud (neid viidi läbi üksnes salaja), vaimulikud represseeritud. Kuigi pärast Nõukogude Liidu kokkuvarisemist ja Gruusia-Abhaasia sõda on kiriku- ja usuelu taas elavnenud, jääb innukate usklike arv siiski väikeseks. Mitmete abhaasi autorite toodud näited usulisest sünkretismist sobivad pigem näideteks sekulariseerumise kohta või vähemalt kõnelevad need sünkretiseerumise ja sekulariseerumise komplementaarsusest. Islami ja kristluse rahumeelse kooseksisteerimise kõrval, mida mitmed abhaasi autorid rõhutavad ja esitavad eeskujuandvana, on põhjust rääkida formaalsest religioossusest ja sekulariseerumisest. Viimasel ajal aset leidev abhaasi usu riiklik esiletõstmine on eelkõige osa identiteediloome ja rahvusliku konsolideerimise protsessist, millele samuti loob soodsa pinnase suhteliselt sekulaarne usuline situatsioon.

\section{Kommentaarid}

1 Artikkel on seotud uurimisprojektiga IUT 31-6.

${ }^{2}$ Etnotsentristlikku paganluse mõistet abhaasi autorid pigem väldivad, eelistades abhaasi usku (Tsakvetadze 2009: 50).

${ }^{3}$ Abhaasi ajaloolasel S. Lakobal koguni Kaukaasia kõige vanem kristlik kogukond (Lakoba 2004: 10).

4 Üks abhaasi protorahvastest.

5 Tänapäeva osseetide esivanemad.

${ }^{6}$ Kohati kasutatakse väljendeid nagu “dramaatilised numbrid”, jättes samas täpsemad numbrid esitamata, vt Francis 2011: 66.

7 1897. aasta rahvaloenduse andmetel moodustasid õigeusklikud kristlased Abhaasia elanikkonnast enamuse, neid oli 87 064, võrdluseks moslemeid vaid 11062 . Armeenia kiriku liikmeid oli 6536, luterlasi 954, katoliiklasi 375, juudiusulisi 162 (Gelenava 2011: 366). 


\section{Kirjandus}

Akaba, Natella $2000=$ Akaba, Natella. O nekotorykh populiarnykh mifakh ( $\mathrm{k}$ istorii gruzino-abkhazskikh vzaimootnoshenii). Garb, Paula \& Inal-Ipa, Arda \& Zakareishvili, Paata (toim). Aspekty gruzino-abkhazskogo konflikta 2. Materialy gruzino-abkhazskoi konferentsii, lk 9-19. Irvine: University of California (https://www.peacebuilding.uci. edu/files/progs/pdfs/russian2.pdf - 17. jaanuar 2019).

Akhaladze, Lia 2016. Monuments of Material Culture of Georgia - Abkhazia. Gamakharia, Jemal \& Akhaladze, Lia (toim). Problems of History, Politics and Culture of Abkhazia, Georgia. Tbilisi: Levan Titmeria, lk 64-86.

Antšabadze, Zurab 1976 = Anchabadze, Z. V. Ocherk etnicheskoi istorii abkhazskogo naroda. Sukhumi: Alashara.

Argun, Juri 2014 = Argun, Iu. G. Iz istorii $i$ etnografii abkhazskoi diaspory. Sukhum: Akademiia Nauk Abkhazii.

Atšugba, Teimuraz 2011a = Achugba, T. A. Istoriia Abkhazaii v datakh. Sukhum (http:// apsnyteka.org/file/Achugba_Istoriya_Abkhazii_v_datah.pdf - 17. jaanuar 2019).

Atšugba, Teimuraz 2011b = Ачугба, Т. А. О некоторых особенностях абхазского феодализма. Абхазоведение V-VI. Сухум: Академия Наук Абхазии, lk 217-227.

Avidzba, Aslan 2008 = Avidzba, A. F. Otechestvennaia voina (1992-1993 gg.). Voprosy voenno-politicheskoi istorii Abkhazii. Sukhum.

Broido, Anna 2010 = Broido, A. Nepokornyi umiraet stoia: voina 1992-1993 godov $i$ etnopsikhologiia abkhazov. Sukhum: Nauchnoe izdanie.

Bartsõts, Ruslan 2012 = Bartsyts R. M. Abkhazy i kazachestvo: mnogovekovye traditsii dobrososedstva. Abhazovedenie 7. Sukhum: Akademiia Nauk Abkhazii, lk 86-110.

Basarija, Simon 2003 = Basariia, Simon 2003 [1923]. Abkhaziia v geograficheskom, etnograficheskom i ekonomicheskom otnoshenii. Sukhum: Ministerstvo obrozovaniia RA.

Bgažba, Oleg \& Lakoba, Stanislav 2015 = Bgazhba, O. Kh. \& Lakoba, S. Z. Istoriia Abkhazii s drevneishikh vremen do nashikh dnei. Sukhum: Ministerstvo obrazovaniia i nauki RA (http://www.abkhazovedenie.com/files/eBooks/41/Bgazhba._Lakoba_Istoriya_ Abkhazii_s_drevnosti_do_nashih_dney.pdf - 19. jaanuar 2019).

Braukämper, Ulrich 1992. Aspects of Religious Syncretism in Southern Ethiopia. Journal of Religion in Africa 22 (3), lk 194-207 (doi: 10.2307/1580916).

Dzidzaria, Georgi 1975 = Dzidzaria, G. A. Makhadzhirstvo i problemy istorii Abkhazii XIX stoletiia. Sukhumi: Alashara.

Dzidzarija, Georgi 1979 = Dzidzariia, G. A. Formirovanie dorevoliutsionnoi abkhazskoi intelligentsii. Sukhumi: Alashara.

Ešba, Elana 2012 = Eshba, E. D. Sovremennaia religioznaia situatsiia v Abkhazii. Vestnik 4. Sukhum: Akademiia Nauk Abkhazii, lk 8-13.

Francis, Céline 2011. Conflict resolution and status. The Case of Georgia and Abkhazia (1989-2008). Brussels: VUB Press. 
Gadnani, Anzor \& Džakeli, Keti 2006 = Gadnani, Anzor \& Dzhakeli, Keti 2006. "Taina" gruzino-abkhazskogo protivostoianiia. Tbilisi: Tetri kalaki.

Gamakharia, Jemal 2016. Abkhazia/Georgia: Historical and Political Problems. Gamakharia, Jemal \& Akhaladze, Lia (toim). Problems of History, Politics and Culture of Abkhazia, Georgia. Tbilisi: Levan Titmeria, lk 9-63.

Geldenhuys, Deon 2009. Contested States in World Politics. Hampshire: Palgrave Macmillan, Basingstoke.

Gelenava, Irakli 2011 = Abkhazia from 1881 till February of 1917. Assays from the History of Georgia. Abkhazia from ancient times till the present days. Tbilisi: Ministry of Education and Culture of Abkhazia, lk 359-384.

Grayson, James Huntley 1992. The Accommodation of Korean Folk Religion to the Religious Forms of Buddhism: An Example of Reverse Syncretism. Asian Folklore Studies 51 (2), lk 199-217 (doi: 10.2307/1178332).

Gumba 2011 = Gumba, A. R. Naturalisticheskaia religiia abkhazov - istochnik mirovozzreniia, nravstvennosti i etiki. Abkhazovedenie. Arkheologia. Istoria. Etnologia. V-VI. Sukhum: Akademiia Nauk Abkhazii, lk 320-328.

Gunba, Mihhail 1989 = Gunba M. M. Abkhaziia v I tysiacheletii n. e.: Sotsial'no-ekonomicheskie i politicheskie otnosheniia. Sukhumi: Alashara.

Helme, Mart 2008. Abhaasia - pika viha kibedad viljad. Maailma Vaade 6, lk 24-25 (http://www.maailmavaade.ee/nr-6/abhaasia-pika-viha-kibedad-viljad-mart-helme 19. jaanuar 2019).

Jersild, Austin 2000. Faith, Custom, and Ritual in the Borderlands: Orthodoxy, Islam, and the "Small Peoples" of the Middle Volga and the North Caucasus. The Russian Review 59 (4), lk 512-529 (doi: 10.1111/0036-0341.00139).

Kadõrbajev 2014 = Kadyrbaev, A. Sh. Ot osmanskogo poddanstva k soiuzu s Rossiei: pravlenie mamliuka abkhaztsa Ali-beia al'-Kabira v Egipte. 1757-1773. Avidzba, Vassili \& Salakaia, Soslan (toim). Voiny na Kavkaze - uroki istorii. Materialy Mezhdunarodnoi nauchnoi konferentsii, posviashchennoi 20-letiiu nachala Otechestvennoi voiny naroda Abkhazii 1992-1993 gg. Sukhum: AbIGI

Kaslandzija, Naala 2012 = Kaslandziia, N. V. 2012. Ob Abkhazskom katolikosate. Abkhazovedenie VII. Sukhum: AbIGI, lk 74-85.

Khorava, Bežan 2011. Abkhazia in 1810-1880. Assays from the History of Georgia. Abkhazia from ancient times till the present days. Tbilisi: Ministry of Education and Culture of Abkhazia, lk 310-358.

King, Charles 2012. Vabaduse viirastus. Kaukaasia ajalugu. Tallinn: Tänapäev.

Kvitsanija, Mziana 2012 = Kvitsiniia, M. B. Religioznost' kak faktor vliianiia na politicheskie protsessy (na materiale politicheskoi istorii Abkhazii XIX veka). Abhazovedenie VII. Sukhum: AbIGI, lk 182-188.

Krõlov, Aleksandr 2001 = Krylov, A. B. 2001. Religiia i traditsii abkhazov. Tom 1. Mokva: Institut vostokovedeniia RAN. 
Lakoba 2000 = Lakoba, Stanislav. Gruzino-abkhazskie otnosheniia v kontekste Rossiiskoi politiki na Kavkaze. Garb, Paula \& Inal-ipa, Arda \& Zakareishvili, Paata (toim). Aspekty gruzino-abkhazskogo konflikta 4. Materialy gruzino-abkhazskoi konferentsii: grazhdanskoe obshestvo, bezhentsy, gosudarstvennoe ustroistvo. Moskva, 25-27 marta 2000. g. Irvine: University of California, lk 104-115 (https://www.peacebuilding.uci.edu/ files/progs/pdfs/russian4.pdf - 22. jaanuar 2019).

Lakoba, Stanislav 2001 = Lakoba, Stanislav. Abkhaziia-de-fakto ili Gruziia-de-iure? Sapporo: Hokkaido University.

Lakoba 2004 = Lakoba, Stanislav. Abkhaziia posle dvukh imperii XIX-XXI vv. Slavic Eurasian Studies 5. Sapporo: Hokkaido University Press.

Leopold, Anita Maria \& Jensen, Jeppe Sinding 2014a. Conclusion. Leopold, Anita Maria \& Jensen, Jeppe Sinding (toim). Syncretism in Religion. A Reader. London, New York: Routledge, lk 376-388.

Leopold, Anita Maria \& Jensen, Jeppe Sinding 2014b. Introduction to part II. Leopold, Anita Maria \& Jensen, Jeppe Sinding (toim). Syncretism in Religion. A Reader. London, New York: Routledge, lk 14-28.

Manutscharjan, Aschot 2009. Die innenpolitische Entwicklung Georgiens vom 1991 bis 1996 unter besonderer Berücksichtigung der Sezessionskonflikte. Reiter, Erich (toim). Die Sezessionskonflikte in Georgien. Wien, Köln, Weimar: Böhlau Verlag, lk 71-100.

Martin, Luter H. 2014. Syncretism, historcism, and cognition: a response to Michael Pye. Leopold, Anita Maria \& Jensen, Jeppe Sinding (toim). Syncretism in Religion. A Reader. London, New York: Routledge, lk 286-294.

North, J. A. 1984. Syncretism (Roman). Hinnells, John N. (toim). The Penguin dictionary of religions. Harmondsworth: Penguin Books.

Papaskiri, Zurab 2010 = Papaskiri, Zurab. Abkhaziia. Istoriia bez fal'sifikatsii. Tbilisi: Izdatel'stvo Sukhumskogo Gosudarstvennogo Universiteta.

Pye, Michael 2014. Syncretism and Ambiguity. Leopold, Anita Maria \& Jensen, Jeppe Sinding (toim). Syncretism in Religion. A Reader. London, New York: Routledge, lk 48-58.

Roemmich, Heinrich 1978. Die Evangelisch-Lutherische Kirche in Russland in Vergangenheit und Gegenwart. Schnurr, Joseph (toim). Die Kirchen und das religiöse Leben der Russlanddeutschen. Evangelischer Teil. Stuttgart: AER Verlag Landsmannschaft der Deutschen aus Russland, lk 1-63.

Smele, Jonathan D. 2015. The Russian civil wars 1916-1926. Ten years that shook the world. Oxford: Oxford University Press.

Smõr 1994 = Smyr, G. V. Religioznye verovanie abkhazov. Gagra.

Stewart, Charles 1999. Syncretism and Its Synonyms: Reflections on Cultural Mixture. Diacritics 29 (3), lk 40-62 (doi: 10.1353/dia.1999.0023). 
Stumpp, Karl 1978. Verzeichnis der ev. Pastoren in den einzelnen deutschen und gemischten Kirchspielen in Russland bzw. Der Sowjetunion, ohne Baltikum und Polen. Schnurr, Joseph (toim). Die Kirchen und das religiöse Leben der Russlanddeutschen. Evangelischer Teil. Stuttgart: AER Verlag Landsmannschaft der Deutschen aus Russland, lk 116-234.

Šamba, Tarass \& Neprošin, Aleksandr 2004 = Shamba, T. M. \& Neproshin, A. Iu. Abkhaziia. Pravovye osnovy gosudartvennosti $i$ suvereniteta. In-Oktavo, Moskva: RGTEU.

Totadze, Anzor 1994. The Population of Abkhazia. The Ossets in Georgia. Tbilisi: Publishing House "Samshoblo".

Tsakvetadze, Gulnara 2009 = Chakvetadze, Gul'nara V. 2009. Konfessional'nye aspekty etnicheskoi kul'tury narodov sovremennoi Abkhazii. Karachaevsk, Sukhum: KarachaevoCherkesskii gosudarstvennyi universitet imeni U. D. Alieva.

\title{
Summary
}

\section{What are the stripes of the Abkhazian flag talking about and what are they silent about? Religious situation in Abkhazia}

\author{
Aivar Jürgenson \\ Senior Research Fellow \\ Institute of History, Archaeology, and Art History, School of Humanities \\ Tallinn University \\ aivarj@tlu.ee
}

Keywords: Abkhazia, Islam, Orthodoxy, secularity, syncretism

When analysing the religious situation in Abkhazia, the Abkhazian authors present it primarily as a peaceful coexistence of different religions - Christianity, Islam, and native Abkhazian religion. Religions that have existed in Abkhazia side by side for centuries have shaped the worldview of the Abkhazians, which, according to some authors, have a strongly syncretistic shape. Along with syncretism and peaceful coexistence of religions, the Abkhazian authors emphasize the deep Christian roots of Abkhazia: many articles and books show how Christianity reached Abkhazia already in the first century, how it became state religion in the 6th-7th centuries, and how the Abkhazians have dealt with the Christian mission in the Caucasus. Sometimes this emphasis has a political background. When the Georgian-Abkhaz War (1992-93) took place, some Georgian politicians in the confrontation with Abkhazians emphasized the religious aspects of the conflict, and even later tried to present Abkhazia as a Muslim country.

The article looks at Abkhazian religious life in the historical perspective and seeks to find explanations for the religious situation today. It also deals with religious image reproduction: Abkhaz authors' efforts to get rid of the Islamic image of Abkhazia created 
by the Georgians. In the Soviet period all religions suffered from anti-religious repressions, mosques and churches of many Christian congregations were closed down, religious rituals were banned and carried out only secretly, and clergymen were repressed. Although after the collapse of the Soviet Union and the war of 1992-93 religious life is allowed again and even favoured by the authorities, the number of eager believers had remained small. Alongside the peaceful coexistence of Islam and Christianity, which is presented by many Abkhaz authors as a good example to be followed by other countries, we also have to speak about formal religiousness and religious secularization. 